\title{
Identifying Direct and Indirect Influences on Vocabulary Development of Children from Low-Income Families from Infancy to Grade 5
}

\author{
Teresa M. Ober ${ }^{1} \&$ Patricia J. Brooks ${ }^{2}$ \\ ${ }^{1}$ University of Notre Dame \\ ${ }^{2}$ College of Staten Island and the Graduate Center, CUNY
}

(Version: 30 January 2022)

Corresponding author: Please address correspondence to: Teresa M. Ober, Ph.D.

(tober@nd.edu), University of Notre Dame, Corbett Family Hall, Notre Dame, IN 46656.

Declaration of interest: None.

CREDiT: Teresa M. Ober: Data Curation, Methodology, Formal analysis, Writing - Original Draft; Patricia J. Brooks: Conceptualization, Methodology, Writing - Review \& Editing, Supervision.

Acknowledgements: The authors would like to acknowledge Anthoula Poulakos, Ph.D. whose prior analysis of the EHSRE dataset led to this study.

Funding: This research did not receive any specific grant from funding agencies in the public, commercial, or not-for-profit sectors. 


\begin{abstract}
We explored how a constellation of factors affected vocabulary development of infants $(N=556$; 49.6\% male) from families comprising the control group of the Early Head Start Research Evaluation project. Predictors assessed at age 14 months accounted for $23.5 \%, 25.8 \%$, and $30.6 \%$ of variance in receptive vocabulary (Peabody Picture Vocabulary Test) at 36 months, Pre$\mathrm{K}$, and Grade 5, respectively. Joint engagement, assessed during free play (3-bags task), and infant cognitive ability (Bayley Mental Development Index) had direct associations with vocabulary knowledge. Gestational age was indirectly associated with vocabulary knowledge via infant cognitive ability. Home environment, maternal education, maternal distress, and child gender had variable direct and/or indirect effects. Latent factors were partially invariant for subgroups with Black/African American and White/European American mothers. Findings suggest a long-term impact of joint engagement on vocabulary growth at least through Grade 5, highlighting the importance of interventions to support mothers and infants living in poverty.
\end{abstract}

keywords: joint engagement; receptive vocabulary; cognitive development; measurement invariance; structural equation model 


\section{Highlights}

- A constellation of factors in infancy predicts receptive vocabulary through Grade 5

- Joint engagement and infant cognitive ability had stable direct effects on vocabulary

- Gestational age had an indirect effect on vocabulary via infant cognitive ability

- Direct/indirect effects of home environment and maternal education varied with age

- Findings highlight importance of interventions to support families living in poverty 
DIRECT INDIRECT INFLUENCES VOCABULARY DEVELOPMENT

\section{Identifying Direct and Indirect Influences on Vocabulary Development of Children from Low-Income Families from Infancy to Grade 5}

Young children growing up in poverty have elevated risk of cognitive and language

delays relative to children from more affluent families (Merz et al., 2019). These children may be at risk of poor developmental and academic outcomes due to differences in the quality of parentchild communication and child-directed speech in the first years of life (Hart \& Risley, 1995;

Hirsh-Pasek et al., 2015). In this investigation, we were interested in understanding how different factors were related within one theoretical model of risk, and how the factors would bear crosslagged associations with later receptive vocabulary development. The overarching goal was to identify how factors associated with the developmental context contribute to a child's resilience in the face of adversity, and whether the associations differ for Black/African American and White/European American children from low-income backgrounds.

\section{Factors that Contribute to Children's Cognitive and Communicative Development}

Contextual and social-environmental factors have been shown to influence children's cognitive and communicative development, including the socio-economic status (SES) of the children's rearing context (Hoff, 2003; Letourneau et al., 2013). Social and economic deprivation puts infants at risk of compromised neurocognitive functioning (Tomalski et al., 2013; Ursache \& Noble, 2016). SES is often measured as a proxy variable directly tied to parental factors including educational attainment, occupational status, and income (Ensminger \& Fothergill, 2003; Farah et al., 2006). Parental education has been shown to influence children's cognitive and communicative development (Duncan \& Magnuson, 2012; Hackman et al., 2015; Noble et al., 2015), such that parents with higher educational attainment are likely to spend more time 
DIRECT INDIRECT INFLUENCES VOCABULARY DEVELOPMENT

with their children (Guryan et al., 2008), engage in higher quality parent-child interactions (Duckworth \& Sabates, 2005), exhibit increased responsiveness and provision of learning materials (Magnuson et al., 2009), use more varied and complex language and speech patterns (Hoff, 2003), and have higher expectations for their child's learning and achievement (DavisKean, 2005). Research also suggests that parenting behaviors have a larger impact on children's school readiness (i.e., prereading skills) in low-income families than in higher income families (Hill, 2001).

Other factors that influence parental behaviors, such as parental distress and mental health, for example, have been shown to vary systematically with SES (Burchinal et al., 2008). Parental distress has been found to place children of Black/African American parents at additional risk (McLoyd, 1990), as they are often denied access to adequate support and resources to cope with poverty-related stressors. The Family Stress Model describes a process by which economic hardship affecting the family unit leads to economic pressures that contribute to psychological distress for parents and disrupted parenting practices that negatively impact children's developmental outcomes (Masarik \& Conger, 2017). While much research has focused on child well-being and socio-emotional adjustment, there is evidence that parental stress and depression also influence children's later cognitive abilities and school achievement (Pearson et al., 2016). Such disparities may be rooted in developmental differences in neurocognitive functioning of children of depressed and nondepressed mothers observed as early as preschool age or approximately 2 to 5 years of age (Lebel et al., 2016).

In addition to differences in material resources associated with SES and systemic inequalities (Yeung \& Conley, 2008), parenting behaviors impacting school-readiness and academic trajectories may vary as a function of culture and ethnicity (Ceballo et al., 2008; Hill, 
DIRECT INDIRECT INFLUENCES VOCABULARY DEVELOPMENT

2001; Hill \& Tyson, 2008). Findings from previous research indicate that race/ethnicity may moderate associations between parenting practices (measured at child's age 12 and 24 months) and children's language development (measured at 18, 24, 30, and 36 months), such that associations between negative and intrusive parenting and children's expressive language development appear to be weaker in Black/African American families than in White/European American families (Pungello et al., 2009). While there is evidence that qualities of parent-child interactions may differ by race/ethnicity, influences of both the quantity (number of different words, number of conversational turns) and complexity (mean length of utterances, whquestions, complex conjunctions) of maternal child-directed speech on children's language outcomes appear to be similar across racial/ethnic groups (Vernon-Feagans et al., 2020).

Home environment. As with parental stress and mental health, the quality of the home environment is another critical construct shown to predict children's developmental outcomes that may vary systematically with SES (Burchinal et al., 2008). The quality of the home environment is often linked to social factors such as the warmth and sensitivity exerted by the parent (Bradley et al., 2001), as well as material factors such as the number of cognitive stimulating toys and books in the home (Payne et al., 1994). Notably, past research has documented that parents of low-income status tend to report greater displays of warmth toward their children than their higher SES counterparts (Pinderhughes et al., 2008).

Child characteristics. From infancy, factors such as the child's gestational age, gender, and early emerging cognitive abilities have been shown to correlate with later cognitive and behavioral outcomes. Children born preterm ( $<37$ weeks) have been found to possess cognitive abilities that are directly proportional to their gestational age $\left(R^{2}=.49, p<.001\right.$; Bhutta et al., 2002). Such early emerging differences in children's abilities may precipitate widening 
DIRECT INDIRECT INFLUENCES VOCABULARY DEVELOPMENT

disparities over time. For instance, at approximately age 10, children who were born very preterm ( $<29$ weeks) were found to have cognitive and perceptual abilities approximately one standard deviation below that of age-matched peers (Stjernqvist \& Svenningsen, 1999).

The child's gender has also been shown to influence cognitive and communicative development by way of differences in the social environment (Lovas, 2011). Variation in the communicative patterns of parental child-directed speech towards female and male infants is evident within the child's first months of life (Johnson et al., 2014), and persists as the infant develops and begins vocalizing (Sung et al., 2013).

Parent-infant joint engagement. Early emerging patterns of parent-infant coordinated engagement have been shown to play a critical role in early language development (Carpenter et al., 1998). The infant's ability to sustain attention while interacting with their mother has been shown to predict vocabulary learning (Çetinçelik et al., 2021; Masek et al., 2021; Yu et al., 2018), is supported by responsive parental behaviors (AUTHOR, 2018; Hirsh-Pasek et al., 2015), and occurs frequently in naturalistic contexts (Suarez-Rivera et al., 2022). Joint engagement - sometimes labeled as "triadic engagement" (E.E. Little et al., 2016) - refers to periods of parent-child interaction that involve active, sustained attending to and interest in a shared topic (Adamson, 2014). Given the emphasis on supported and coordinated activity between a child and their caregiver, which can be observed through overt behavior, joint engagement is regarded as a critical context for joint (shared) attention to objects and events of mutual interest (Adamson et al., 2019). Within the first year and a half, infants' social and communicative abilities undergo rapid development (Bakeman \& Adamson, 1984), with behaviors such as shared attention to objects and events and imitation occurring on a more frequent basis (Charman et al., 2000). Language development is also dependent on child-directed 
speech, which is typically of higher quality within the context of caregiver-child joint engagement. For example, parent-child engagement in shared book-reading and other stimulating activities has been shown to influence the children's language development trajectories (ZajicekFarber, 2010). Findings from the Early Head Start Research Evaluation (EHSRE) project indicated that low-income White/European American families had higher rates of shared bookreading than low-income Black/African American or Hispanic families (Raikes et al., 2006).

Negative mother-infant interaction. Negative parenting behaviors have been found to correlate with diminished language development (Laake \& Bridgett, 2018). In a prior study utilizing hierarchical linear models (Pungello et al., 2009), individual differences in language outcomes at 14, 24, 30, and 36 months were positively associated with maternal sensitivity and negatively associated with intrusiveness in parent-child interactions, with these factors moderated by race/ethnicity and SES. Scores on receptive and expressive language measures were lower for children of Black/African American parents than for children of White/European American parents, with the achievement gap increasing with age. Other research suggests that after controlling for differences in parenting practices, the achievement gap between groups narrows by 25-50\% (Brooks-Gunn \& Markman, 2005).

\section{Modeling Risk with a Constellation of Factors}

Complicating the developmental context even further, factors associated with increased risk of delays often co-occur and cluster together. Cumulative risk indices have been used to examine the compounding influence of environmental risks and are sometimes contrasted with approaches that examine discrete levels or categories of risk (Evans et al., 2013). There is evidence that such indices are predictive of children's developmental outcomes (Burchinal et al., 2000), beyond what is predicted by any single factor (Flouri \& Kallis, 2007). 
DIRECT INDIRECT INFLUENCES VOCABULARY DEVELOPMENT

Given the complexity of the influence of SES on children's language development, we sought to create a model of cumulative risk associated with low income based on measures derived when the child was 14 months of age. We then sought to understand how this model would predict children's later cognitive and communicative development at 36 months of age, and their vocabulary development through Grade 5. We were subsequently interested in determining whether the model would account for variation in outcomes of children regardless of the caregivers' race/ethnicity.

\section{Research Aims}

The current study is an extension of previous work using structural equation models (SEM) to explore individual differences in language outcomes of low-income toddlers in the EHSRE project (AUTHOR, 2020; Poulakos, 2013). AUTHOR (2020) presented a preliminary version of a SEM predicting Bayley MDI scores and PPVT scores at 36 months for subgroups of children in the control group of the EHSRE project who differed in race/ethnicity. Their findings indicated that the strength of associations between variables were highly similar across subgroups. We build on this earlier work by following the children from age 14 months through

Grade 5. The research objectives are as follows:

1. To test for direct and indirect influences of 14 month contextual, maternal, and child factors in predicting scores on a standardized assessment of children's receptive vocabulary knowledge at age 36 months, Pre-K (approximately 4 years) and Grade 5 (approximately 10 years).

Our first aim was to examine how a constellation of child, maternal, and contextual factors observed in infancy might account for individual differences in receptive vocabulary knowledge over time. We tested a model of risk measured at 14 months of age, and determined 
DIRECT INDIRECT INFLUENCES VOCABULARY DEVELOPMENT

whether various factors in the model predicted receptive vocabulary knowledge at age 36 months, Pre-K (approximate age 4 years), and Grade 5 (approximate age 10 years). We predicted that multiple factors measured at 14 months would bear direct and indirect relations to vocabulary knowledge at age 36 months, and expected the same constellation of factors to show persistent associations with vocabulary knowledge at later time points.

2. To determine whether latent constructs have sufficient measurement invariance across children of caregivers from different racial/ethnic subgroups. If strict invariance is not achieved, to determine which parameters vary across groups.

Our second aim was to examine whether the proposed model of risk had invariant measurement properties between Black/African American and White/European American subgroups. To that end, we tested for psychometric invariance on the measurement models for the latent factors to ensure that the subgroup results were comparable.

3. To test whether the 14 month factors might differentially influence receptive vocabulary knowledge for children of Black/African American and White/European American parents.

Our third aim was to determine whether the model was sufficient in accounting for vocabulary development trajectories of Black/African American and White/European American subgroups within the sample. Specifically, we were interested in whether model fit indices might differ substantially for Black/African American and White/European American subgroups over time.

\section{Method}

\section{Participants}

The study utilized a publicly available dataset from Early Head Start Research and 
DIRECT INDIRECT INFLUENCES VOCABULARY DEVELOPMENT

Evaluation project (EHSRE; United States Department of Health and Human Services Administration for Children and Families, 2019a). Names and descriptions of variables used in this analysis are show in Table S1 in Supplemental Materials. All data used in this project are publicly available (see United States Department of Health and Human Services, Administration for Children and Families, 2011). The code used in this analysis has been made publicly available (see AUTHOR, 2021). The Institutional Review Board at the [...name of institution...] (where both authors were affiliated at the time of initial analysis) made the determination that the study was not human subjects research because it uses a publicly available de-identified dataset. The study was not pre-registered.

The analytic sample comprised a subset of children of low-income mothers who were in the control group of the EHSRE study (i.e., not enrolled in Early Head Start programs). The subset consisted of participants of Black/African American or White/European American caregivers who had data for the 36-month receptive vocabulary outcome measure. We excluded children in the treatment group of the EHSRE study to control for variability in Early Head Start program characteristics that might impact children's vocabulary development trajectories. Table 1 provides a summary of the demographic characteristics of the sample $(N=556 ; 280$ girls and 276 boys). Child gender was coded as a binary variable $(0=$ female, $1=$ male). Mothers selfidentified their race/ethnicity as follows: 55.6\% identified as White/European American and 44.4\% as Black/African American. Race/ethnicity of the mother was re-coded as a binary variable (1=Black/African American, 0=White/European American).

Mothers reported their infant's approximate gestational age by selecting one of four choices. Most infants $(84.3 \%)$ were born on time; $1.7 \%$ were born $>2$ months early, $11.9 \%$ were born $>3$ weeks early, and $2.2 \%$ were born $>3$ weeks late. A subset $(2.8 \%)$ of mothers reported 
speaking a language other than English at home. Mothers indicated their highest educational attainment by selecting one of three possible choices: $38.2 \%$ attended some high school, $34.3 \%$ obtained a high school degree/GED, and $27.5 \%$ obtained a degree higher than high school or GED diploma. Family income was on average 59.6\% (SD = 48.9) of the poverty threshold. About one-quarter $(24.1 \%)$ of the sample was living in extremely impoverished circumstances, based on a household income of less than $33 \%$ of the poverty threshold for that year. As shown in the $t$-test comparison in Table 1, the subgroups did not differ with respect to child gender, gestational age, or home language, but differed in maternal education and household income.

Table 1

Sample demographics at child age 14 month

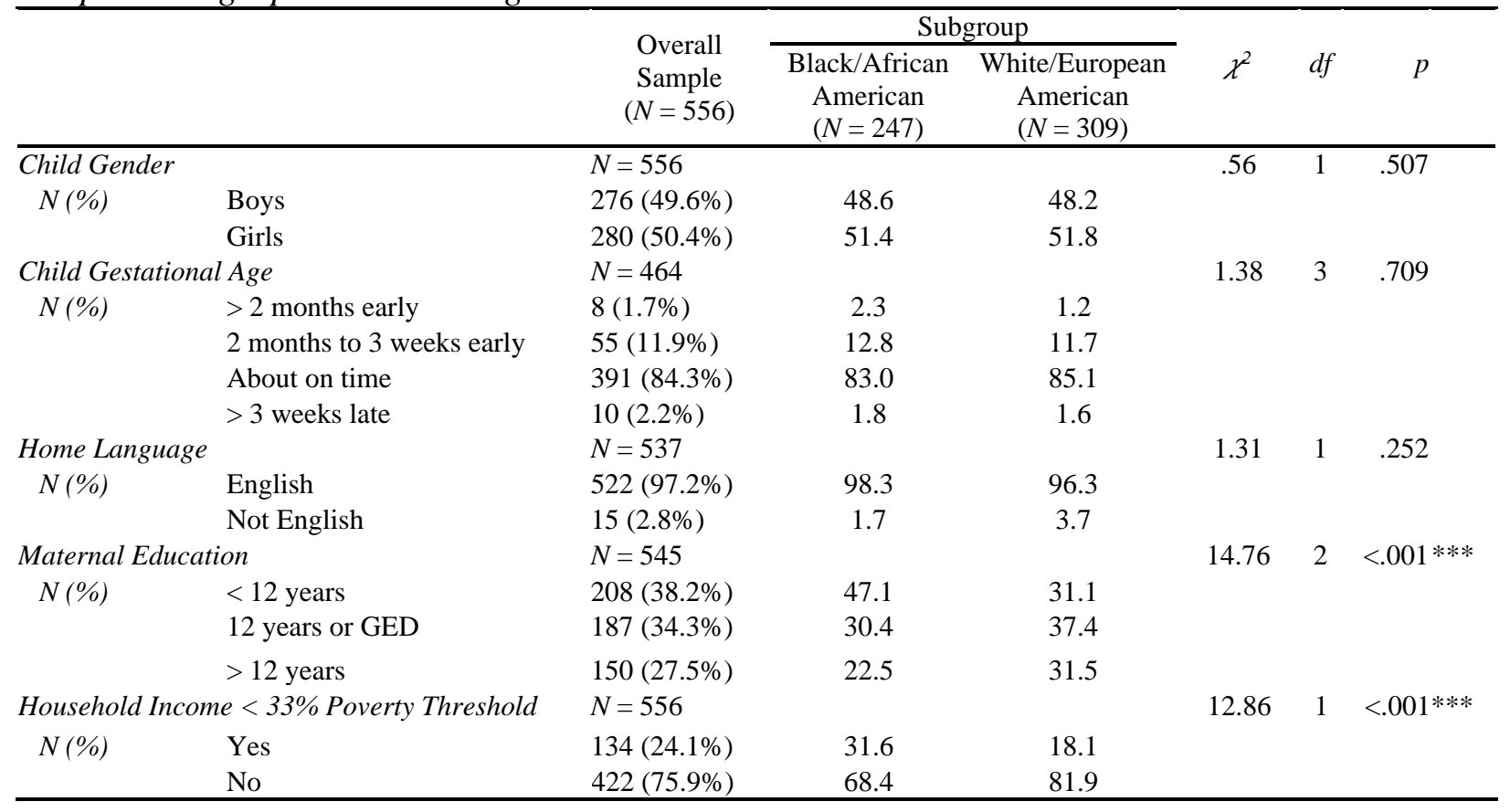

\section{Measures at Child Age 14 Months}

In addition to the demographic variables listed above, measures of infant cognitive ability, the home environment, mother-child interaction, and maternal distress were administered at child age 14 months. Table 2 provides descriptive statistics for each measure along with $t$-tests 
comparing subgroups. Correlations between 14-month predictors and vocabulary outcomes are available in Supplemental Materials (Table S2).

Table 2

Descriptive statistics for measures at child age 14 months

\begin{tabular}{|c|c|c|c|c|c|c|c|c|c|}
\hline \multirow[t]{2}{*}{ 14-month predictors } & \multicolumn{2}{|c|}{ Overall Sample } & \multicolumn{2}{|c|}{$\begin{array}{c}\text { Black/African } \\
\text { American }\end{array}$} & \multicolumn{2}{|c|}{$\begin{array}{c}\text { White/ European } \\
\text { American } \\
\end{array}$} & \multirow[b]{2}{*}{$t$} & \multirow[b]{2}{*}{$p$} & \multirow[b]{2}{*}{$d$} \\
\hline & $N$ & $M(S D)$ & $N$ & $M(S D)$ & $N$ & $M(S D)$ & & & \\
\hline Bayley MDI & 426 & $98.5(10.9)$ & 173 & $97.3(9.8)$ & 253 & $99.3(11.6)$ & -1.88 & .061 & -.179 \\
\hline HOME Inventory & 473 & $26.6(3.3)$ & 201 & $25.4(3.5)$ & 272 & $27.5(2.8)$ & -6.79 & $<.001 * * *$ & -.653 \\
\hline \multicolumn{10}{|l|}{ 3-bag Task } \\
\hline Parent Supportiveness & 441 & $4.0(1.0)$ & 185 & $3.6(1.0)$ & 256 & $4.3(1.0)$ & -7.47 & $<.001 * * *$ & -.722 \\
\hline Child Engagement of Parent & 441 & $3.9(1.1)$ & 185 & $3.9(1.2)$ & 256 & $3.9(1.0)$ & -.33 & .741 & -.033 \\
\hline Child Sustained Attention & 441 & $5.0(1.0)$ & 185 & $4.7(1.0)$ & 256 & $5.2(0.9)$ & -6.12 & $<.001 * * *$ & -.598 \\
\hline Parent Intrusiveness & 441 & $2.4(1.3)$ & 185 & $2.8(1.3)$ & 256 & $2.1(1.1)$ & 6.12 & $<.001 * * *$ & .606 \\
\hline Parent Negative Regard & 441 & $1.5(0.8)$ & 185 & $1.7(1.0)$ & 256 & $1.3(0.6)$ & 5.17 & $<.001 * * *$ & .539 \\
\hline Child Negativity toward Parent & 441 & $2.1(1.1)$ & 185 & $2.3(1.2)$ & 256 & $1.9(1.0)$ & 3.79 & $<.001 * * *$ & .379 \\
\hline \multicolumn{10}{|l|}{ Maternal Distress Variables } \\
\hline CES-D Depression Scale & 496 & $14.0(10.1)$ & 218 & $13.7(9.8)$ & 278 & $14.2(10.4)$ & -.57 & .570 & -.051 \\
\hline Parent Distress Inventory & 502 & $27.2(9.4)$ & 222 & $28.1(9.9)$ & 280 & $26.5(9.0)$ & 1.82 & .069 & .166 \\
\hline Parent-Child Dysfunctional Interaction & 502 & $17.2(5.7)$ & 222 & $17.5(6.6)$ & 280 & $16.9(4.9)$ & 1.51 & .132 & .111 \\
\hline
\end{tabular}

Infant cognitive ability. Children completed the Bayley Scales of Infant Development

(BSID; Bayley, 1993), a norm-referenced test that measures mental and motor development in infants from one to 42 months of age. BSID scores are used to describe the developmental functioning of infants and to assist in diagnosis and treatment planning for infants with developmental delays or disabilities. The Mental Development Index (MDI) measures the cognitive, language, and personal-social development of children under 31/2 years of age (Bayley, 1993). We used infants' standardized MDI scores in the model. At 14 months, scores on the MDI $($ mean $=98.5, S D=10.9)$ approximated the population mean $(\mu=100, \sigma=15)$, with no significant difference between subgroups, see Table 2.

HOME Inventory. Participants completed the Home Observation for the Measurement of the Environment (HOME) inventory (Caldwell \& Bradley, 1984), which measures the quality of stimulation and support available to a child in the home environment. The infant/toddler HOME inventory is designed for use between birth and age three and consists of a combination of 
DIRECT INDIRECT INFLUENCES VOCABULARY DEVELOPMENT

parental self-report items and interviewer-observed items. The inventory assesses the quality of the mother's speech and verbal responses to the child during the home visit (as rated by the interviewer); whether the parent encourages the child to learn shapes, colors, numbers, and the alphabet; the presence of books, toys, and games accessible to the child; and whether the parent reads to the child several times per week. A total score was derived from the infant/toddler HOME inventory and used in the model, with higher scores indicating a more stimulating and supportive home environment. As shown in Table 2, scores on the HOME inventory varied significantly between the two subgroups. After controlling for household income (income as $\%$ of poverty line for family) and maternal education $(1=$ Completed less than 12 years of schooling, 2 = Completed 12 years of school or a GED, 3 = Completed more than 12 years of schooling), subgroup differences in scores on the HOME inventory remained significant (see Table S3 in Supplemental Materials).

3-bag task. The 3-bag task is a semi-structured play procedure used to assess positive and negative aspects of parent-child interaction. The mother and child are given three bags of interesting toys and asked to play with the toys in sequence to facilitate parent-child interaction (United States Department of Health and Human Services, Administration for Children and Families, 2019b). Bag 1 contained the picture book Good Dog, Carl (Day, 1986), bag 2 contained a set of kitchen utensils, pots, pans, and a stove, and bag 3 contained a Noah's ark and animal set. The semi-structured play task was videotaped; subsequently, child and maternal behaviors were scored in accordance with the 3-bag task coding scales (NICHD Early Child Care Research Network, 1999; Ware, Brady, O’Brien, \& Berlin, 2000). From this measure, we used 6 of the 7 behavioral scales: parent supportiveness, child engagement of parent, child sustained attention, parent intrusiveness, parent negative regard, and child negativity toward parent. 
DIRECT INDIRECT INFLUENCES VOCABULARY DEVELOPMENT

The parent supportiveness scale assessed maternal sensitivity, positive affect, and the extent to which the mother provided cognitive stimulation while interacting with her child. The child engagement of parent scale assessed the extent to which the child made communicative bids to engage with their mother and whether they expressed positive regard towards her. The child sustained attention scale assessed the extent to which children demonstrated focused attention and engagement with the book or toy set provided. Scores reflected the extent to which the child was involved vs. disorganized in attending to the objects. The parent intrusiveness scale assessed the extent to which the mother attempted to control the child rather than recognizing and respecting the child's autonomy. Parent negative regard assessed the mother's expressed discontent with, anger toward, disapproval of, or rejection of the child. The child negativity toward parent scale reflected the extent to which the child engaged in negative behaviors such as aggressively rejecting a toy or hitting/throwing an object in response to their mother. Possible scores on each scale ranged from 1 to 7; intraclass correlations on coders' responses ranged from .68 to .76 , with percent agreement within 1 point (range $87 \%$ to $96 \%$; Fuligni \& Brooks-Gunn, 2013). Table 2 provides $t$-test comparisons of the two subgroups. Except for the child engagement of the parent scale, all other 3-bag task scales showed significant differences between the two subgroups. Even when controlling for household and maternal education, all the subgroup differences remained significant (see Table S3 in Supplemental Materials).

Center for Epidemiological Studies-Depression Inventory (CES-D). The mothers completed the CES-D (Radloff, 1977), which measures symptoms of depression using a 20-item scale. Respondents were asked the number of days in the past week they had particular symptoms such as poor appetite, restlessness, loneliness, sadness, and lack of energy. Though the CES-D does not indicate a diagnosis of clinical depression, it does discriminate between 
DIRECT INDIRECT INFLUENCES VOCABULARY DEVELOPMENT

depressed and not depressed patients on the number of depressive symptoms, with higher scores indicating more symptoms. Mean scores on the CES-D did not differ significantly for the two subgroups, see Table 2.

Short-form version of the Parental Stress Index (PSI-SF). The PSI-SF (Abidin, 1995) measures the degree of stress within the parent-child relationship attributable to three possible sources: the child's temperament, parental depression, and negative reinforcement. The Parental Distress Index was derived from 12-items on the PSI-SF. It served as an indicator of the level of distress the parent feels in the role of parent stemming from personal factors, including a low sense of parenting competence, stress due to the perceived restrictions associated with parenting, depression, and general lack of social support. The Parent-Child Dysfunctional Interaction Index was also derived from 12-items on the PSI-SF. It served as an indicator of whether the parent either perceives that the child is abusing or rejecting them, or feels disappointed in or alienated from the child. For each index, higher scores indicated greater maternal distress. Mean scores for the Parental Distress Index and the Parent-Child Dysfunctional Interaction Index did not differ for the two subgroups, see Table 2.

\section{Receptive vocabulary knowledge at 36 months, Pre-K, and Grade 5}

Children's receptive vocabulary knowledge was measured at three ages (36 months, preK, and Grade 5) using standardized age-normed scores from the Peabody Picture Vocabulary Test (PPVT-III; Dunn \& Dunn, 1997), an untimed verbal intelligence test of approximately 2030 minutes duration. The examiner presents four pictures at a time to the child and the child is asked to point to the picture that matches a word spoken aloud. The test continues until the child has made errors on a set number of trials. The PPVT-III is normed for ages 2.5 to 90 years. Table 3 provides descriptive statistics for the PPVT scores on each occasion of measurement. 
Standardized scores increased over time. Whereas mean scores on the PPVT-III at age 36 months $($ mean $=83.2, S D=16.0)$ were more than one SD below the population mean score $(\mu=$ $100, \sigma=15)$, children's scores at Grade 5 approximated the population mean $($ mean $=96.5, S D=$ 15.5). Subgroup differences in PPVT-III scores were statistically significant at each time point and appeared to increase over time; see Table 3 for $t$-test comparisons and effect-size estimates. The PPVT scores were moderately correlated across the three time points $(r$ values $=.56-.71, p s$ $<.001)$, indicating stability in individual differences. When controlling for household and maternal education, the subgroup differences in PPVT scores remained significant (see Table S4 in Supplemental Materials).

Table 3. Descriptive statistics for PPVT scores at child age 36 months, 4 years, and Grade 5

\begin{tabular}{|c|c|c|c|c|c|c|c|c|c|}
\hline \multirow[t]{2}{*}{ Age } & \multicolumn{2}{|c|}{ Overall Sample } & \multicolumn{2}{|c|}{$\begin{array}{c}\text { Black/African } \\
\text { American }\end{array}$} & \multicolumn{2}{|c|}{$\begin{array}{c}\text { White/ European } \\
\text { American }\end{array}$} & \multirow[b]{2}{*}{$t$} & \multirow[b]{2}{*}{$p$} & \multirow[b]{2}{*}{$d$} \\
\hline & $N$ & $M(S D)$ & $N$ & $M(S D)$ & $N$ & $M(S D)$ & & & \\
\hline 36 months & 556 & $83.2(16.0)$ & 247 & $78.5(14.7)$ & 309 & $86.9(16.0)$ & 6.43 & $<.001 * * *$ & .554 \\
\hline Pre-K & 445 & $93.0(14.8)$ & 192 & $85.6(14.1)$ & 253 & $98.6(12.7)$ & 10.12 & $<.001 * * *$ & .982 \\
\hline Grade 5 & 377 & $96.5(15.5)$ & 168 & $88.7(14.0)$ & 209 & $102.8(13.7)$ & 9.81 & $<.001 * * *$ & 1.02 \\
\hline
\end{tabular}

\section{Results}

We used structural equation modeling (SEM) to explore how a constellation of factors assessed at infancy (14 months) was associated with receptive vocabulary knowledge (PPVT-III scores) of children from low-income families at ages 36 months, Pre-K, and Grade 5. As a first step in model building, a measurement model was created using confirmatory factor analysis (CFA) to define three latent variables (joint engagement, negative interaction, maternal distress) in terms of the corresponding indicator variables. As a second step, we conducted measurement invariance on each of the latent factors, comparing a series of successively more constrained factor models. We then used SEM to determine direct and indirect effects of the various factors on receptive vocabulary knowledge at each age and whether the strength of the observed relations differed between subgroups. 


\section{Measurement Models}

We used the lavaan (Rosseel, 2012) package in $R$ to conduct CFA, which served to establish the adequacy of the indicator variables for the three latent variables. Full information robust maximum likelihood estimation was used to handle missing data (Acock, 2012).

Standardized coefficients were reported and model fit was assessed using multiple indices (Hu \& Bentler, 1999), including the chi-square test, comparative fit index (CFI), Tucker-Lewis index (TLI), root mean square error of approximation (RMSEA), and standardized root mean square residual (SRMR).

Joint engagement. The latent variable joint engagement was measured using three observed variables derived from the 3-bag task (Fuligni \& Brooks-Gunn, 2013): child sustained attention, child engagement of parent, and parental supportiveness of the child. The CFA produced acceptable model fit indices, $C F I=1.00, T L I=1.00, R M S E A<.001, S R M R<.001$, with standardized loadings for all manifest variables above .50, see Figure 1 for the results for the full sample and each subgroup.

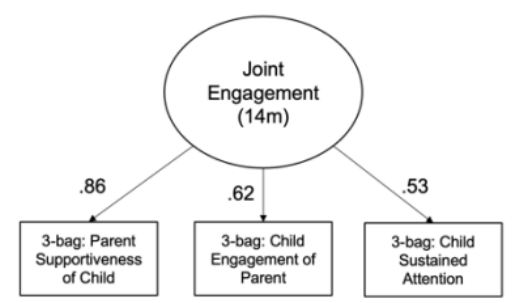

a.

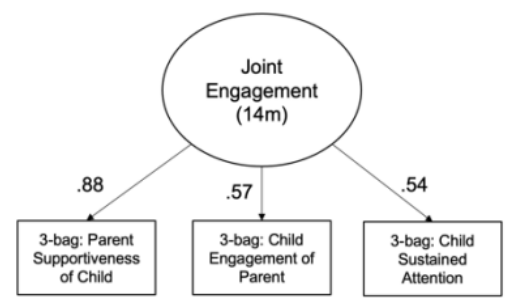

b.

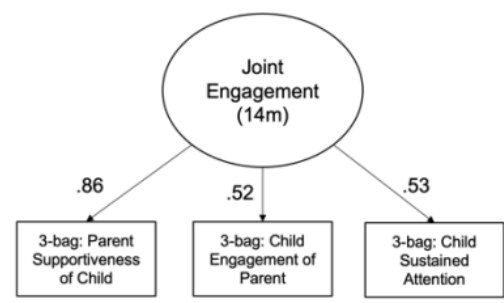

c.

Figure 1. Latent variable for joint engagement measured at 14 months for (a) total sample $(N=556)$, (b) Black / African American sample $(N=247)$, and White / European American sample $(N=309)$

Negative interaction. The latent variable negative interaction was also derived from three observed variables derived from the 3-bag task: parent negative regard of the child, parent intrusiveness, and child negativity toward parent. The CFA for negative interaction produced acceptable model fit indices, $C F I=1.00, T L I=1.00, R M S E A<.001, S R M R<.001$, with 
standardized loadings for all manifest variables above .40 , see Figure 2 for the results for the full sample and each subgroup.

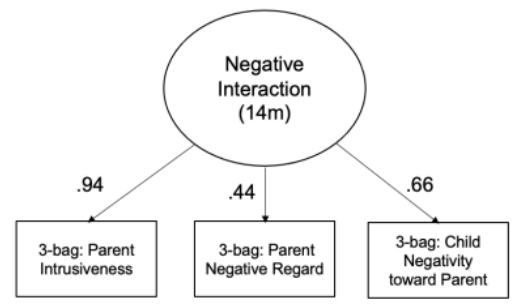

a.

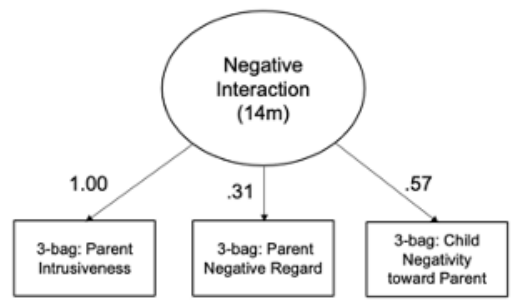

b.

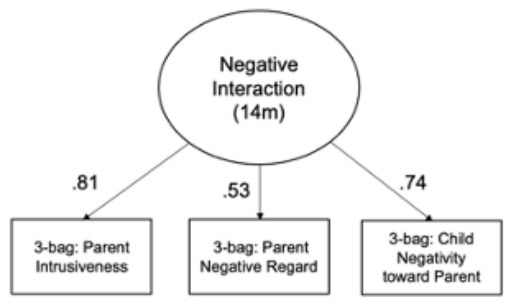

c.

Figure 2. Latent variable for negative interaction measured at 14 months for (a) total sample $(N=556)$,

(b) Black / African American sample $(N=247)$, and White / European American sample $(N=309)$

Maternal distress. The latent variable maternal distress was derived from scores on the CES-D scale (Radloff, 1997), and the Parental Distress Index and Parent-Child Dysfunctional Interaction Index of the PSI-SF (Abidin, 1995). The CFA for maternal distress produced acceptable model fit indices, $C F I=1.00, T L I=1.00, R M S E A<.001, S R M R<.001$, with standardized loadings for all manifest variables above .50 , see Figure 3 for the results for the full sample and each subgroup.

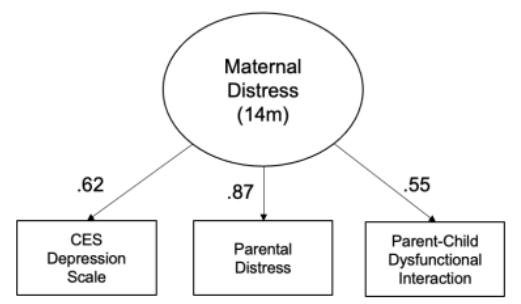

a.

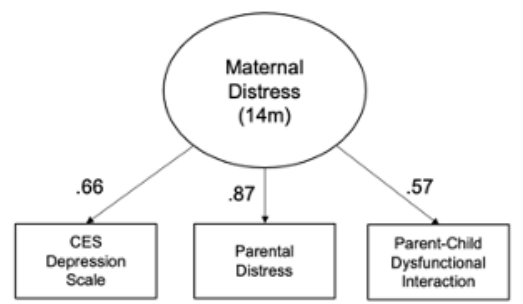

b.

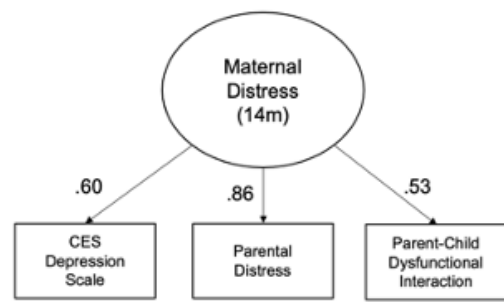

c.

Figure 3. Latent variable for maternal distress measured at 14 months for (a) total sample $(N=556)$, (b)

Black / African American sample $(N=247)$, and White / European American sample $(N=309)$

Measurement invariance. Having confirmed good fit indices for each latent variable for the full sample using CFA, we then tested for equivalence of measurement (i.e., measurement invariance) between Black/African American and White/European American subgroups using multi-group CFA. Measurement invariance for each latent variable and for the full SEM was 
tested using the strategy proposed by Jöreskog $(1971,1993)$, which compares the model fit of two groups against a theoretical model using a series of models with increasingly more constrained parameters (see Milfont \& Fischer, 2010; Putnick \& Bornstein, 2016), see Table 4. We sought to establish, at a minimum, evidence of metric invariance (i.e., loadings constrained between groups) between the two subgroups (Guenole \& Brown, 2014; Hsiao \& Lai, 2018) in order to proceed with fitting the SEMs. In determining whether the assumption of invariance held at a given level of model constraint, we evaluated multiple fit indices, including the results of the $\chi^{2}$ difference test, as well as the $\Delta$ CFI (Cheung \& Rensvold, 2002), Akaike Information Criterion (AIC) and Bayesian Information Criterion (BIC) values. Lower AIC and BIC values generally provide evidence of a more parsimonious factor model (Byrne et al., 1989).

Table 4

Sequence of models tested to establish measurement invariance

\begin{tabular}{|l|l|}
\hline Model & Constraints \\
\hline Configural & $\begin{array}{l}\text { Same latent model structure between groups. Subgroups are tested with no } \\
\text { additional equivalence constraints. }\end{array}$ \\
\hline Metric & $\begin{array}{l}\text { Same model as the "configural model," with the addition of constraints of } \\
\text { equivalence on factor loadings between the groups. }\end{array}$ \\
\hline Scalar & $\begin{array}{l}\text { Same model and constraints as the "metric model," with the addition of } \\
\text { constraints of equivalence on intercepts between the groups. }\end{array}$ \\
\hline Strict & $\begin{array}{l}\text { Same model and constraints as the "scalar model," with the addition of } \\
\text { constraints of equivalence on residuals between the groups. }\end{array}$ \\
\hline
\end{tabular}

Table 5 shows the fit indices based on robust estimation for each of the successively more constrained models that were tested in conducting the measurement invariance analysis. The findings provide evidence of adequate measurement invariance (i.e., metric invariance with the factor loadings constrained) based on the $\chi^{2}$ difference test and relative decrease in AIC/BIC for each of the latent variables. For joint engagement, measurement invariance was achieved at 
the level of the metric model; for negative interaction and maternal distress, measurement invariance was achieved at the level of the scalar model.

Table 5

Comparison of model fit indices for the latent variables models comparing Black/African American and White/European American subgroups with increasing equality constraints $(N=$ 556)

\begin{tabular}{|c|c|c|c|c|c|c|c|c|c|c|c|c|c|c|c|}
\hline \multirow[b]{2}{*}{ Constraints } & \multirow[b]{2}{*}{$\chi^{2}$} & \multirow[b]{2}{*}{$d f$} & \multirow[b]{2}{*}{$p$} & \multirow[b]{2}{*}{ CFI } & \multirow[b]{2}{*}{$T L I$} & \multirow[b]{2}{*}{ RMSEA } & \multirow[b]{2}{*}{$S R M R$} & \multirow[b]{2}{*}{$A I C$} & \multirow[b]{2}{*}{$B I C$} & \multicolumn{5}{|c|}{ Model Comparison } & \multirow[b]{2}{*}{ Decision } \\
\hline & & & & & & & & & & & $\Delta d f$ & $p$ & $\Delta d f$ & $\triangle C F I$ & \\
\hline \multicolumn{16}{|l|}{ Joint Engagement } \\
\hline Configural & - & - & - & 1.00 & 1.00 & $<.001$ & $<.001$ & 3566.44 & 3640.04 & - & - & - & - & - & - \\
\hline Metric & 0.10 & 2 & 0.95 & 1.00 & 1.02 & $<.001$ & 0.01 & 3562.53 & 3627.96 & Metric v. Configural & 2 & .953 & 2 & .00 & Accept \\
\hline Scalar & 26.23 & 4 & $<.001$ & 0.91 & 0.86 & 0.16 & 0.07 & 3584.67 & 3641.92 & Scalar v. Metric & 2 & $<.001$ & 2 & .09 & Reject \\
\hline Strict & 34.83 & 8 & $<.001$ & 0.89 & 0.92 & 0.12 & 0.09 & 3585.27 & 3626.16 & Strict v. Scalar & 4 & .055 & 4 & .01 & - \\
\hline \multicolumn{16}{|l|}{ Negative Interaction } \\
\hline Configural & - & - & - & 1.00 & 1.00 & 0.00 & 0.00 & 3404.06 & 3477.67 & - & - & - & - & - & - \\
\hline Metric & 2.63 & 2 & 0.27 & 1.00 & 0.99 & 0.04 & 0.02 & 3402.69 & 3468.12 & Metric v. Configural & 2 & .538 & 2 & .00 & Accept \\
\hline Scalar & 10.22 & 4 & 0.04 & 0.98 & 0.97 & 0.08 & 0.05 & 3406.29 & 3463.53 & Scalar v. Metric & 2 & .132 & 2 & .02 & Accept \\
\hline Strict & 99.99 & 8 & $<.001$ & 0.67 & 0.75 & 0.23 & 0.25 & 3488.06 & 3528.95 & Strict v. Scalar & 4 & $<.001$ & 4 & .31 & Reject \\
\hline \multicolumn{16}{|l|}{ Maternal Distress } \\
\hline Configural & - & - & - & 1.00 & 1.00 & 0.00 & 0.00 & 10248.17 & 10324.1 & - & - & - & - & - & - \\
\hline Metric & 2.75 & 2 & 0.25 & 1.00 & 0.99 & 0.04 & 0.03 & 10246.91 & 10314.41 & Metric v. Configural & 2 & .430 & 2 & .00 & Accept \\
\hline Scalar & 8.00 & 4 & 0.09 & 0.99 & 0.98 & 0.06 & 0.04 & 10248.16 & 10307.23 & Scalar v. Metric & 2 & .060 & 2 & .01 & Accept \\
\hline Strict & 33.10 & 8 & $<.001$ & 0.92 & 0.94 & 0.11 & 0.12 & 10265.27 & 10307.45 & Strict v. Scalar & 4 & .007 & 4 & .07 & Reject \\
\hline
\end{tabular}

Note: Bold font indicates the level at which assumptions of invariance failed.

\section{Structural Equation Modeling}

Having established measurement invariance between subgroups across all three latent constructs, we then sought to examine the direct and indirect effects of each of the predictors on receptive vocabulary development. Table S5 in Supplemental Materials shows the results of a preliminary regression model with vocabulary outcomes predicted by demographic factors. Predictors in the SEMs were measured at 14 months and included demographic variables (i.e., child gender, gestational age, maternal education) found to explain variation in receptive vocabulary at 36 months, along with the home environment (HOME Total Score), child's cognitive ability (Bayley MDI), maternal distress, negative interaction, and joint engagement variables. Receptive vocabulary knowledge (PPVT-III scores) as an outcome was measured at 36 months (3 years), in Pre-K (approximately 4 years), and Grade 5 (approximately 10 years). For 
each successive model, the dataset was restricted to a subset of data used in the previous model. For example, data used in the model predicting variation in the children's vocabulary measured in Pre-K also contained data for the 36-month outcome. Subsequently, data used in the model predicting variation in children's vocabulary in Grade 5 also contained data points for both the 36 month and Pre-K vocabulary measurements. The generic model, with all paths tested, is shown in Figure 4.

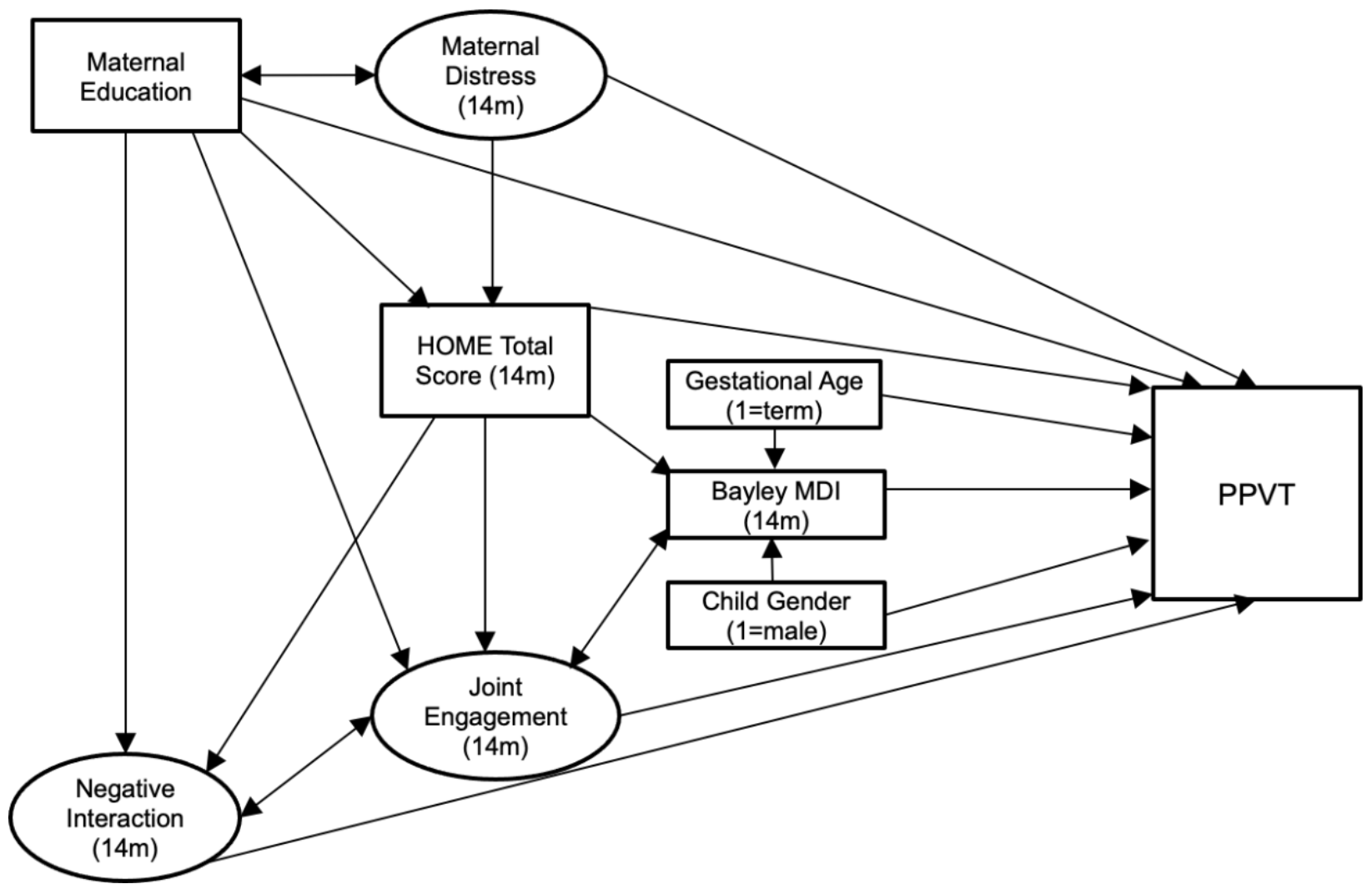

Figure 4. Generic model showing all direct effects; Indirect paths estimated include the following: HOME $\rightarrow$ Bayley MDI $\rightarrow$ PPVT; HOME $\rightarrow$ Joint engagement $\rightarrow$ PPVT; Maternal distress $\rightarrow$ HOME $\rightarrow$ PPVT; Maternal education $\rightarrow$ Joint engagement $\rightarrow$ PPVT; Maternal education $\rightarrow$ HOME $\rightarrow$ PPVT; Gestational age $\rightarrow$ Bayley MDI $\rightarrow$ PPVT; Child gender $\rightarrow$ Bayley MDI $\rightarrow$ PPVT

The predictors were examined in relation to PPVT-III scores at each age in separate SEMs using full information robust maximum likelihood estimation. First, the model was fit on the full sample. Subsequently, we conducted subgroup analysis with all three latent factors entered into the SEMs at the highest level of constraint previously achieved: factor loadings were 
DIRECT INDIRECT INFLUENCES VOCABULARY DEVELOPMENT

constrained for joint engagement, while factor loadings and intercepts were constrained for negative interaction and maternal distress. Prior to conducting the subgroup analyses, goodness of fit indices were examined in the full model and evaluated with the same criteria mentioned previously. We expected that the model would implicate qualities of parent-child interaction in both subgroups as measured at child age 14 months on subsequent vocabulary development, while also pointing to a broader range of factors impacting outcomes (i.e., significant paths) that might differ between the Black/African American and White/European American subgroups.

36-month model. The SEM predicting variation in PPVT standardized scores for the full sample at 36 months is shown in Figure 5. The full model with unconstrained factor loadings and intercepts demonstrated good fit, $\chi^{2}(d f=76, n=556)=161.627, p<.001, C F I=0.935, T L I=$ $0.910, R M S E A=0.046[0.036,0.056], S R M R=0.052$. Though the chi-square test indicated imperfect fit, the test is highly sensitive to sample size (Brown, 2015; T.D. Little, 2013), and its significance should be considered in relation to the other indices demonstrating acceptable fit. With the overall sample, approximately $23.5 \%$ of variance in the children's vocabulary scores was accounted for by the model. 


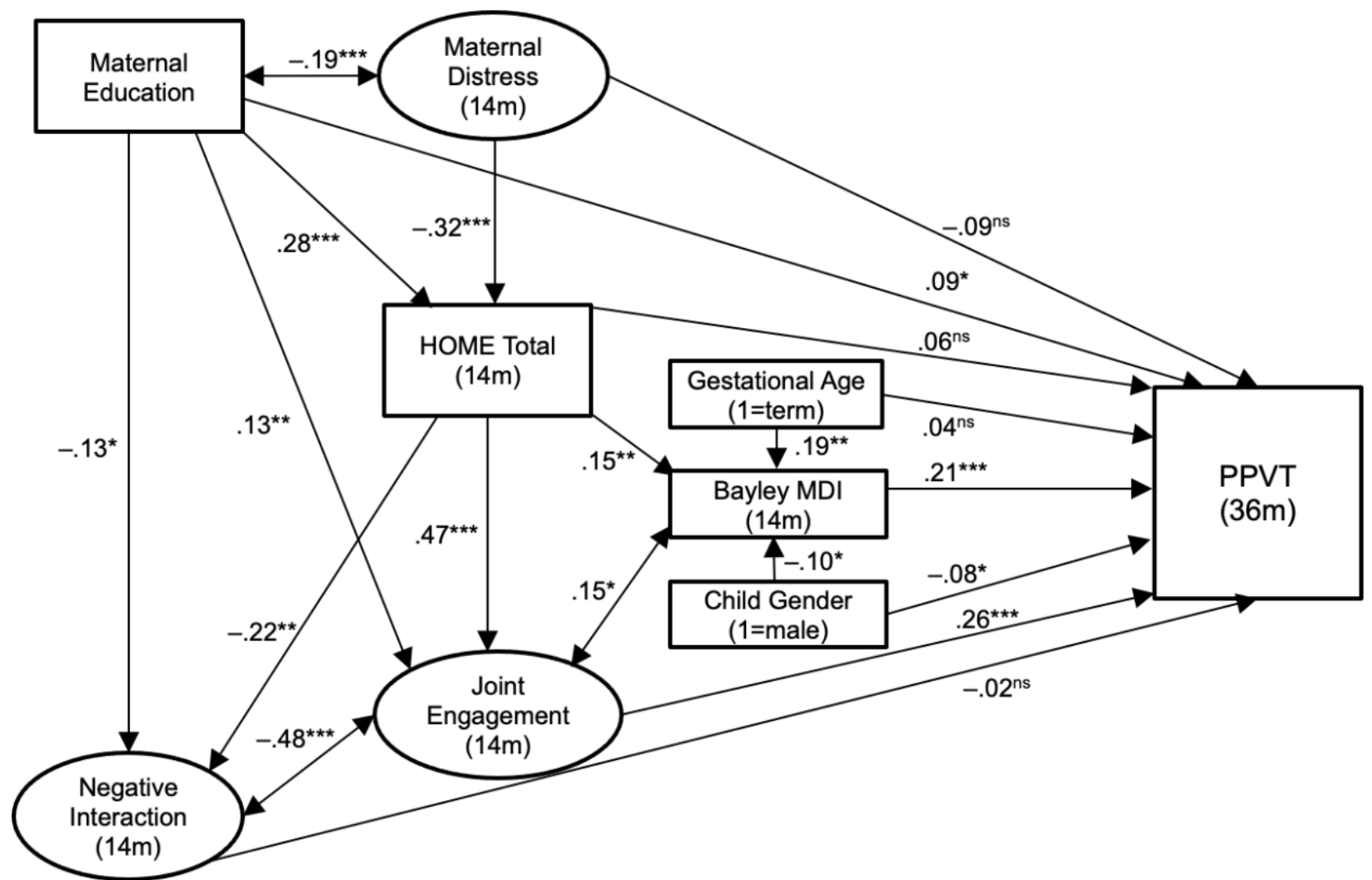

Figure 5. Standardized estimates of the model predicting PPVT scores at 36 months for the entire sample. Note: $* * * p<.001, * * p<.01, * p<.05,{ }^{\mathrm{ns}} p \geq .05$

As shown in Figure 5, several of the 14-month variables had a significant direct effect on receptive vocabulary knowledge at 36 months. In order of magnitude, based on standardized estimates of effects, were significant direct effects of joint engagement, infant cognitive ability (Bayley MDI), maternal education, and child gender (favoring girls). Notably, although negative interaction co-varied significantly with joint engagement, it did not have a direct effect in predicting vocabulary knowledge at 36 months. Similarly, the home environment (HOME total score) was not directly associated with vocabulary knowledge, but was associated with both indicators the quality of mother-infant interaction (i.e., positively with joint engagement and negatively with negative interaction) as well as infant cognitive ability. Maternal distress was also not directly associated with vocabulary knowledge at 36 month, but accounted for 
significant variance in the quality of the home environment and covaried (negatively) with maternal education.

Table 6 provides a summary of tests of the indirect effects in the model. Joint engagement appeared to mediate the association between the quality of home environment and children's vocabulary knowledge, with evidence of a significant indirect and total effect in the absence of a direct effect. Joint engagement appeared to partially mediate the relation between maternal education and vocabulary knowledge. These findings highlight the importance of joint engagement not only as a direct contributor to later vocabulary development, but also one as a factor that influences the effect of maternal and home factors. With regard to infant cognitive ability as a possible mediator, we found some evidence of an indirect effect of the home environment on vocabulary scores by way of Bayley MDI scores, but, there was no evidence of a total effect. The same was true for gestational age: There was evidence of an indirect effect of gestational age on vocabulary scores by way of Bayley MDI scores though the total effect was not significant. 
Table 6

Indirect and total effects estimated for model with 36m PPVT scores

\begin{tabular}{|c|c|c|c|c|c|c|}
\hline & Std. Estimate $(\beta)$ & $S E$ & $\begin{array}{l}95 \% \text { CI } \\
\text { (Lower) }\end{array}$ & $\begin{array}{l}95 \% \text { CI } \\
\text { (Upper) }\end{array}$ & $z$ & $p$ \\
\hline \multicolumn{7}{|c|}{ Child Gender $\rightarrow$ Bayley MDI $\rightarrow$ PPVT } \\
\hline Indirect & -0.02 & 0.01 & -0.04 & 0.00 & -1.90 & $0.058 \cdot$ \\
\hline Total & -0.10 & 0.04 & -0.18 & -0.03 & -2.67 & $0.008 * *$ \\
\hline \multicolumn{7}{|c|}{ Gestational Age $\rightarrow$ Bayley MDI $\rightarrow$ PPVT } \\
\hline Indirect & 0.04 & 0.02 & 0.01 & 0.07 & 2.57 & $0.010 *$ \\
\hline Total & 0.08 & 0.04 & -0.01 & 0.16 & 1.82 & 0.068 . \\
\hline \multicolumn{7}{|c|}{ HOME $\rightarrow$ Bayley MDI $\rightarrow$ PPVT } \\
\hline Indirect & 0.03 & 0.01 & 0.01 & 0.06 & 2.51 & $0.012 *$ \\
\hline Total & 0.09 & 0.06 & -0.03 & 0.22 & 1.52 & 0.128 \\
\hline \multicolumn{7}{|c|}{ HOME $\rightarrow$ Joint Engagement $\rightarrow$ PPVT } \\
\hline Indirect & 0.12 & 0.05 & 0.03 & 0.21 & 2.59 & $0.010 *$ \\
\hline Total & 0.18 & 0.06 & 0.07 & 0.30 & 3.20 & $0.001 * *$ \\
\hline \multicolumn{7}{|c|}{ Maternal Distress $\rightarrow$ HOME $\rightarrow$ PPVT } \\
\hline Indirect & -0.02 & 0.02 & -0.06 & 0.02 & -1.00 & 0.315 \\
\hline Total & -0.11 & 0.05 & -0.20 & -0.02 & -2.32 & $0.020 *$ \\
\hline \multicolumn{7}{|c|}{ Maternal Education $\rightarrow$ Joint Engagement $\rightarrow$ PPVT } \\
\hline Indirect & 0.03 & 0.02 & 0.00 & 0.07 & 2.04 & $0.042 *$ \\
\hline Total & 0.12 & 0.04 & 0.04 & 0.21 & 2.90 & $0.004 * *$ \\
\hline \multicolumn{7}{|c|}{ Maternal Education $\rightarrow$ HOME $\rightarrow$ PPVT } \\
\hline Indirect & 0.02 & 0.02 & -0.02 & 0.05 & 0.99 & 0.322 \\
\hline Total & 0.11 & 0.04 & 0.02 & 0.19 & 2.49 & $0.013 *$ \\
\hline
\end{tabular}

Note: $* * * p<.001, * * p<.01, * p<.05, \cdot p<.10$

Subgroups. Analyses were conducted to examine differences in parameter estimates for the Black/African American $(n=247)$ and White/European American $(n=309)$ subgroups. Model fit generally appeared acceptable for both the Black/African American $\left(\chi^{2}(d f=105)=\right.$ $588.67, p<.001, C F I=.931, T L I=.904, R M S E A=.043[.025, .060], S R M R=.067)$ and White/European $\left(\chi^{2}(d f=105)=809.27, p<.001, C F I=.892, T L I=.851, R M S E A=.060[.046\right.$, $.073], S R M R=.061)$ subgroups. The model accounted for $16.3 \%$ of variation in PPVT standardized scores at 36 month in the Black/African American subgroup, and $21.9 \%$ in the White/European American subgroup. For each subgroup, the strength of the regression paths shown in Figure 5 were similar to those in the full model. Table S6 in Supplemental Materials shows all standardized parameters estimates for SEM for the model fit to both subgroups separately. 
Pre-K model. The SEM predicting variation in PPVT standardized scores for the full sample in Pre-K is shown in Figure 6. The model with unconstrained factor loadings and intercepts demonstrated good fit, $\chi^{2}(d f=76, n=445)=135.773, p<.001, C F I=0.945, T L I=$ $0.923, R M S E A=0.043[0.031,0.055], S R M R=0.052$. The model accounted for approximately $25.8 \%$ of variance in receptive vocabulary scores at Pre-K.

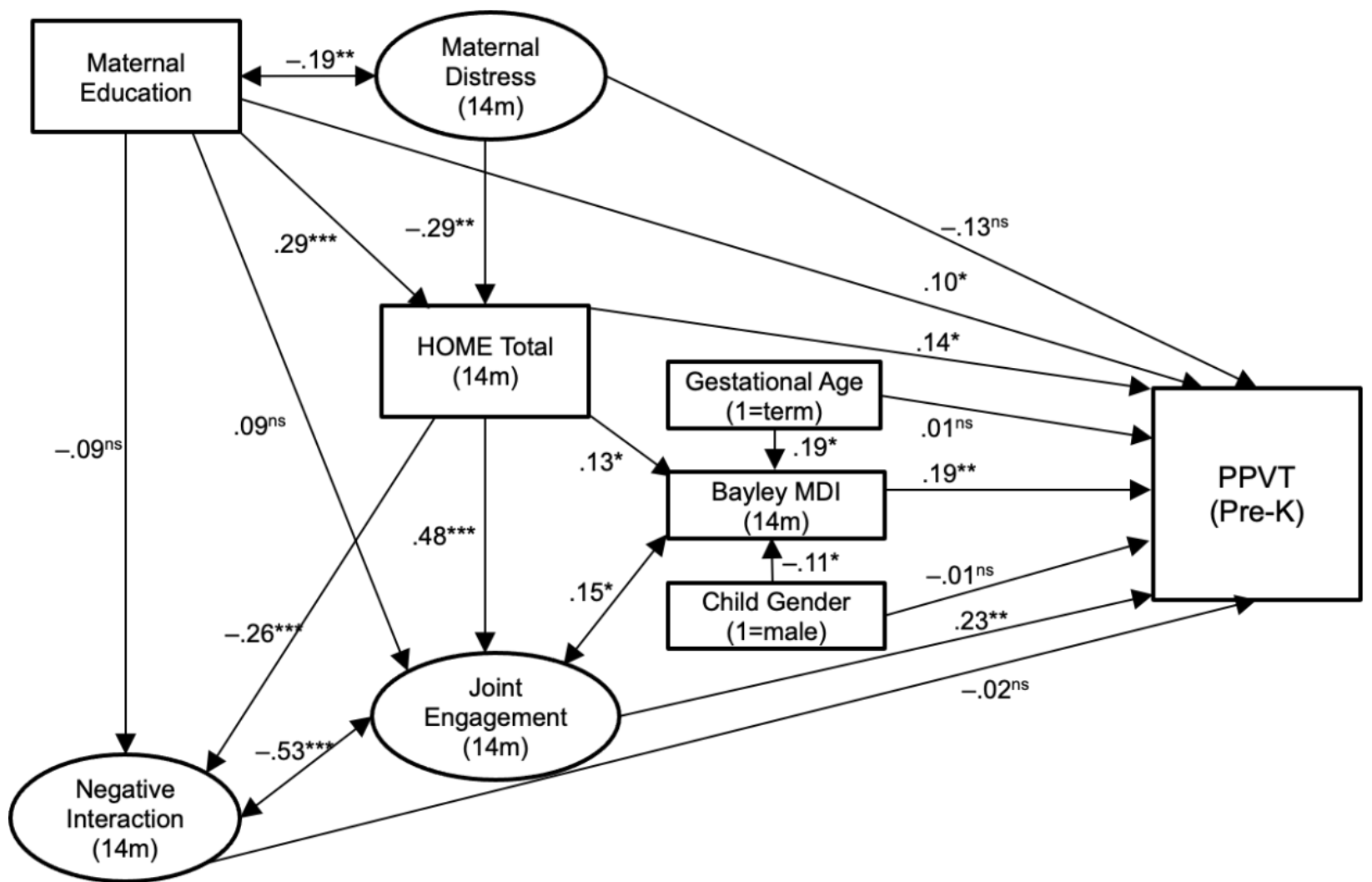

Figure 6. Standardized estimates of the model predicting PPVT scores in Pre-K. Model shows estimates for the entire sample. Note: $* * * p<.001, * * p<.01, * p<.05,{ }^{\text {ns }} p \geq .05$

As shown in Figure 6, several of the 14-month variables still had significant direct effects on receptive vocabulary knowledge at Pre-K, or approximately 4 years of age. In order of magnitude, based on standardized estimates of effects, were significant direct effects of joint engagement, infant cognitive ability (Bayley MDI), home environment (HOME total score), and maternal education. The direct effects matched what was observed at 36 months, with two exceptions: home environment was significant in predicting PPVT scores at pre-K but not at 36 
months; child gender (favoring girls) was significant in predicting PPVT scores at age 36 months, but not at pre-K. As in the 36-month model, negative interaction co-varied with joint engagement, but did not have a direct effect on vocabulary knowledge. Also matching the results at 36 months, maternal distress did not have a direct effect on vocabulary knowledge, but was associated with the home environment and maternal education.

Table 7 summarizes the tests of indirect effects in the pre-K model. Joint engagement no longer appeared to mediate the association between the quality of home environment and children's vocabulary knowledge at pre-K. The home environment, in turn, mediated effects of maternal distress (as indicated by significant indirect and total effects in the absence of a direct effect) and partially mediated effects of maternal education on vocabulary knowledge (as indicated by significant direct, indirect and total effects). Taken together, the results suggest a persistent influence of the home environment on receptive vocabulary development over time, over and above its association with joint engagement. In addition, as was the case at 36 months, the indirect effect of gestational age on vocabulary scores by way of Bayley MDI scores was significant in the pre-K model, though the total effect was not significant. 
Table 7

Indirect and total effects estimated for model with Pre-K PPVT scores

\begin{tabular}{|c|c|c|c|c|c|c|}
\hline & Std. Estimate $(\beta)$ & $S E$ & $\begin{array}{l}95 \% \text { CI } \\
\text { (Lower) }\end{array}$ & $\begin{array}{l}95 \% \mathrm{CI} \\
\text { (Upper) }\end{array}$ & $z$ & $p$ \\
\hline \multicolumn{7}{|c|}{ Child Gender $\rightarrow$ Bayley MDI $\rightarrow$ PPVT } \\
\hline Indirect & -0.02 & 0.01 & -0.04 & 0.00 & -1.87 & 0.062 \\
\hline Total & -0.03 & 0.04 & -0.12 & 0.05 & -0.74 & 0.457 \\
\hline \multicolumn{7}{|c|}{ Gestational Age $\rightarrow$ Bayley MDI $\rightarrow$ PPVT } \\
\hline Indirect & 0.03 & 0.02 & 0.00 & 0.06 & 2.21 & $0.027 *$ \\
\hline Total & 0.05 & 0.04 & -0.04 & 0.13 & 1.09 & 0.277 \\
\hline \multicolumn{7}{|c|}{ HOME $\rightarrow$ Bayley MDI $\rightarrow$ PPVT } \\
\hline Indirect & 0.02 & 0.01 & 0.00 & 0.05 & 1.85 & 0.064 \\
\hline Total & 0.17 & 0.06 & 0.04 & 0.29 & 2.61 & $0.009 * *$ \\
\hline \multicolumn{7}{|c|}{ HOME $\rightarrow$ Joint Engagement $\rightarrow$ PPVT } \\
\hline Indirect & 0.11 & 0.05 & 0.02 & 0.20 & 2.39 & $0.017 *$ \\
\hline Total & 0.25 & 0.06 & 0.14 & 0.37 & 4.21 & $<.001 * * *$ \\
\hline \multicolumn{7}{|c|}{ Maternal Distress $\rightarrow$ HOME $\rightarrow$ PPVT } \\
\hline Indirect & -0.04 & 0.02 & -0.08 & 0.00 & -2.10 & $0.036 *$ \\
\hline Total & -0.17 & 0.06 & -0.28 & -0.06 & -2.93 & $0.003 * *$ \\
\hline \multicolumn{7}{|c|}{ Maternal Education $\rightarrow$ Joint Engagement $\rightarrow$ PPVT } \\
\hline Indirect & 0.02 & 0.02 & -0.01 & 0.05 & 1.34 & 0.180 \\
\hline Total & 0.12 & 0.05 & 0.03 & 0.21 & 2.53 & $0.011 *$ \\
\hline \multicolumn{7}{|c|}{ Maternal Education $\rightarrow$ HOME $\rightarrow$ PPVT } \\
\hline Indirect & 0.04 & 0.02 & 0.00 & 0.08 & 2.15 & $0.031 *$ \\
\hline Total & 0.14 & 0.05 & 0.05 & 0.23 & 3.06 & $0.002 * *$ \\
\hline
\end{tabular}

Note: $* * * p<.001, * * p<.01, * p<.05, \cdot p<.10$

Subgroups. Model fit indices remained acceptable for the Black/African American $\left(\chi^{2}(d f\right.$ $=105, n=192)=475.49, p<.001, C F I=.948, T L I=.928, R M S E A=.037[<.001, .058]$, SRMR $=.069)$ and White/European American $\left(\chi^{2}(d f=105, n=253)=719.40, p<.001, C F I=.907\right.$, $T L I=.871, R M S E A=.057[.041, .072], S R M R=.063)$ subgroups. The model accounted for $14.6 \%$ of variation in PPVT standardized scores at pre-K in the Black/African American subgroup, and $32.1 \%$ in the White/European American subgroup. As was the case at 36 months, the subgroups models at pre-K largely matched the results for the full sample shown in Figure 6 (see Table S7 in Supplemental Materials for standardized parameters estimates for SEMs fitted to each subgroup separately).

Grade 5 model. The SEM predicting variation in PPVT standardized scores for the full sample in Grade 5 is shown in Figure 7. The full-sample model with unconstrained factor 
loadings and intercepts demonstrated good fit, $\chi^{2}(d f=76, n=322)=108.683, p<.001, C F I=$ $0.960, T L I=0.945, R M S E A=0.052[0.020,0.053], S R M R=0.052$. The model accounted for approximately $30.6 \%$ of variance in vocabulary scores in Grade 5.

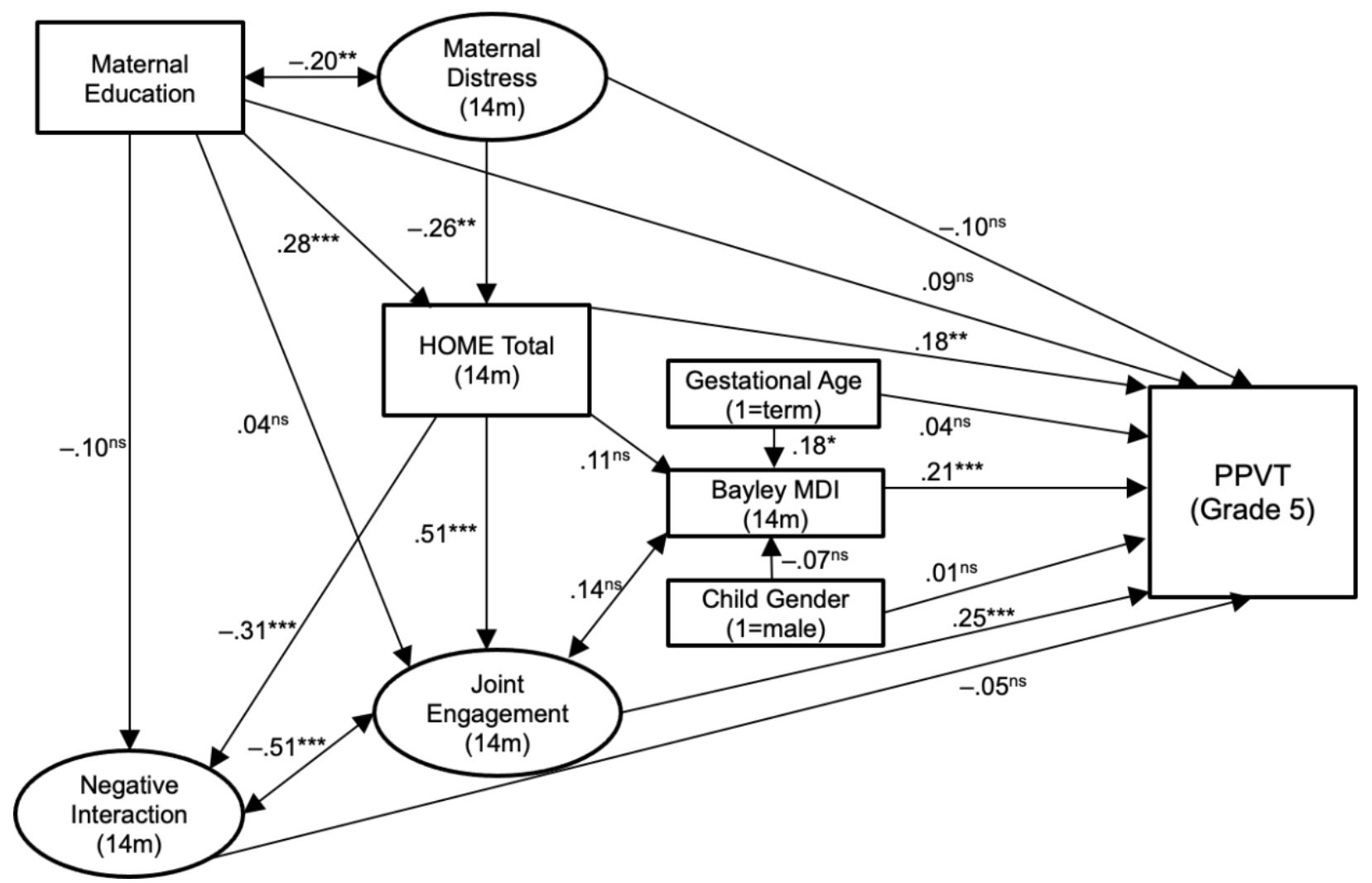

Figure 7. Standardized estimates of the model predicting PPVT scores in Grade 5. Model shows estimates for the entire sample. Note: $* * * p<.001, * * p<.01, * p<.05,{ }^{\text {ns }} p \geq .05$

As shown in Figure 7, several of the 14-month variables continued to show significant direct effects on receptive vocabulary knowledge at Grade 5, or approximately 10 years of age. In order of magnitude, based on standardized estimates of effects, were significant direct effects of joint engagement, infant cognitive ability (Bayley MDI), and the home environment (HOME total score). The direct effects matched what was observed at pre-K, with one exception: the direct effect of maternal education on receptive vocabulary knowledge was significant at pre-K, but not at Grade 5. In other respects, the models at pre-K and Grade 5 were similar. 
Table 8

Indirect and total effects estimated for model with Grade 5 PPVT scores

\begin{tabular}{|c|c|c|c|c|c|c|}
\hline & Std. Estimate $(\beta)$ & $S E$ & $\begin{array}{l}95 \% \mathrm{CI} \\
\text { (Lower) }\end{array}$ & $\begin{array}{l}95 \% \text { CI } \\
\text { (Upper) }\end{array}$ & $z$ & $p$ \\
\hline \multicolumn{7}{|c|}{ Child Gender $\rightarrow$ Bayley MDI $\rightarrow$ PPVT } \\
\hline Indirect & -0.01 & 0.01 & -0.04 & 0.01 & -1.09 & 0.275 \\
\hline Total & 0.00 & 0.05 & -0.10 & 0.10 & -0.04 & 0.968 \\
\hline \multicolumn{7}{|c|}{ Gestational Age $\rightarrow$ Bayley MDI $\rightarrow$ PPVT } \\
\hline Indirect & 0.04 & 0.02 & 0.00 & 0.07 & 2.09 & $0.036 *$ \\
\hline Total & 0.07 & 0.05 & -0.03 & 0.18 & 1.38 & 0.167 \\
\hline \multicolumn{7}{|c|}{ HOME $\rightarrow$ Bayley MDI $\rightarrow$ PPVT } \\
\hline Indirect & 0.02 & 0.02 & -0.01 & 0.05 & 1.49 & 0.136 \\
\hline Total & 0.20 & 0.06 & 0.08 & 0.33 & 3.18 & $0.001 * *$ \\
\hline \multicolumn{7}{|c|}{ HOME $\rightarrow$ Joint Engagement $\rightarrow$ PPVT } \\
\hline Indirect & 0.12 & 0.05 & 0.03 & 0.22 & 2.51 & $0.012 *$ \\
\hline Total & 0.30 & 0.07 & 0.17 & 0.44 & 4.54 & $<.001 * * *$ \\
\hline \multicolumn{7}{|c|}{ Maternal Distress $\rightarrow$ HOME $\rightarrow$ PPVT } \\
\hline Indirect & -0.05 & 0.02 & -0.09 & 0.00 & -2.09 & $0.037 *$ \\
\hline Total & -0.15 & 0.06 & -0.27 & -0.02 & -2.31 & $0.021 *$ \\
\hline \multicolumn{7}{|c|}{ Maternal Education $\rightarrow$ Joint Engagement $\rightarrow$ PPVT } \\
\hline Indirect & 0.01 & 0.02 & -0.02 & 0.04 & 0.66 & 0.510 \\
\hline Total & 0.10 & 0.05 & 0.01 & 0.20 & 2.08 & $0.037 *$ \\
\hline \multicolumn{7}{|c|}{ Maternal Education $\rightarrow$ HOME $\rightarrow$ PPVT } \\
\hline Indirect & 0.05 & 0.02 & 0.01 & 0.09 & 2.54 & $0.011 *$ \\
\hline Total & 0.14 & 0.05 & 0.05 & 0.24 & 2.85 & $0.004 * *$ \\
\hline
\end{tabular}

Note: $* * * p<.001, * * p<.01, * p<.05$

Table 8 summarizes the tests of indirect effects in the Grade 5 model. As was seen in the pre-K model, joint engagement partially mediated the association between the quality of home environment and children's vocabulary knowledge at Grade 5. Maternal education and maternal distress both continued to have an indirect effect on vocabulary knowledge, mediated by the home environment. Once again, there appeared to be an indirect effect of gestational age by way of Bayley MDI scores though the total effect was not significant.

Subgroups. Though fit indices were not as good as the models with the early outcomes, they generally had acceptable fit for the Black/African American $\left(\chi^{2}(d f=105, n=135)=428.99\right.$, $p<.001, C F I=.890, T L I=.848, R M S E A=.059[.034, .081], S R M R=.079)$ and White/European American $\left(\chi^{2}(d f=105, n=187)=549.12, p<.001, C F I=.942, T L I=.920\right.$, $R M S E A=.044[.018, .064], S R M R=.062)$ subgroups. The model accounted for $20.1 \%$ of 
DIRECT INDIRECT INFLUENCES VOCABULARY DEVELOPMENT

variation in PPVT standardized scores at Grade 5 in the Black/African American subgroup, and $30.0 \%$ in the White/European American subgroup. Again, the models for the two subgroups at

Grade 5 were similar to that of the full sample shown in Figure 7 (see Table S8 in Supplemental Materials for standardized parameters estimates for SEMs fitted to each subgroup separately).

\section{Discussion}

For children growing up in poverty, individual differences in developmental outcomes have been linked to factors that originate in the first years of life (Ursache \& Noble, 2016). The current study used SEM to tease apart direct and indirect influences of child and maternal characteristics, home environment, and parent-infant interactional dynamics in infancy in predicting receptive vocabulary of low-income Black/African American and White/European American children at ages 36 months to Grade 5 (approximately 10 years). We used CFA to test the adequacy of three latent variables serving as indices of joint engagement, negative motherinfant interaction and maternal distress. After testing the adequacy of the latent variables, we established a best-fitting SEM for the full sample. We conducted a measurement invariance analysis to determine whether the SEM showed acceptable fit indices for Black/African American and White/European American participant subgroups. Testing for measurement invariance is important especially given that Black/African American and White/European American families experience differential hardship and risk due to structural inequalities and systemic prejudice, which may affect psychometric equivalence (Brooks-Gunn \& Markman, 2005; Putnick \& Bornstein, 2016).

Starting with the child factors, we observed a direct effect of 14-month infant cognitive ability (Bayley MDI) on receptive vocabulary outcomes (PPVT) at 36 months of age, in Pre-K, and in Grade 5, indicating considerable stability in intellectual abilities over the first decade of 
DIRECT INDIRECT INFLUENCES VOCABULARY DEVELOPMENT

life (Bornstein et al., 2004). Gestational age had significant indirect effects on vocabulary outcomes at each of the three time points by way of 14-month cognitive ability, indicating that children who were not born within three-weeks of term tended to have lower Bayley MDI scores, which impacted their receptive vocabulary development over time. Prior research indicates a long-term impact of prematurity on language development (Bee et al., 1982). Our findings suggest that early differences in general cognitive abilities mediate the impact of prematurity on vocabulary development. Though gender (favoring girls over boys) has also been linked with individual differences in language abilities at 2 to 5 years of age (Bornstein et al., 2004), the direct effect of gender on receptive vocabulary knowledge was significant only at 36 months. At pre-K and Grade 5, there were no direct or indirect effects of gender on PPVT scores.

With regard to maternal characteristics, maternal educational attainment had a significant direct effect and indirect effect via joint engagement in predicting children's receptive vocabulary at age 36 months and in Pre-K, but not in Grade 5. In line with previous research (Christian et al., 1998; Dollaghan et al., 1999), we found maternal educational attainment to be positively associated with children's receptive vocabulary knowledge. The indirect effect of maternal education indicates that joint engagement was enhanced for children of mothers with greater educational attainment and for children living in more emotionally supportive and cognitively stimulating homes. The latent variable maternal distress did not have a significant direct effect on receptive vocabulary scores at any age, but was indirectly associated with PPVT scores at pre-K and Grade 5 via the home environment. Previous research found that infants with mothers exhibiting depressive symptoms tended to have lower receptive vocabulary knowledge at older ages than infants of non-depressed mothers (Ahun et al., 2017; Letourneau et al., 2013); other research found a negative (concurrent) association between parenting stress (PSI-SF 
DIRECT INDIRECT INFLUENCES VOCABULARY DEVELOPMENT

scores) and children's PPVT scores at 2 to 4 years of age (Noel et al., 2008). In our study, the two maternal variables (maternal distress, maternal education) exhibited significant negative covariance and contributed in opposite ways to the quality of the home environment, which in turn, was associated with PPVT scores. Taken together, these results indicate the importance of supporting maternal mental health and providing educational opportunities for mothers living in low-income communities as effective means of fostering their children's cognitive and academic development.

The quality of the home environment has been found to have a significant and stable association with language development, even after accounting for SES (Melvin et al., 2017). Children in developmentally stimulating environments are more likely to be exposed to learning materials such as books and toys that facilitate parent-child engagement. In the present study, we found that the direct effect of the quality of the home environment on vocabulary knowledge was significant only at Pre-K (approximately 4 years) and Grade 5 (approximately 10 years). In addition to its direct effect at select time points, the home environment indirectly influenced vocabulary knowledge via joint engagement, with a significant indirect effect at each time point. Taken together, these findings suggest that the quality of the home environment measured in infancy thus appears to have a cumulative influence on vocabulary development that extends through Grade 5. Of all the variables in the model, the latent variable joint engagement had the strongest direct effect on vocabulary development at each of the three time points. Joint engagement consisted of measures of child sustained attention, child engagement of parent, and parent supportiveness taken from the 3-bag task, an observational measure of parent-infant interaction at 14 months. As indicated by the results of the CFA, these three measures were closely linked, as was expected (Adamson et al., 2019). In the context of joint engagement, 
supportive parents aid children's cognitive and linguistic development by providing vocabulary that is relevant to the child's focus of attention (Tamis-LeMonda et al., 2001; Yu et al., 2019).

In addition to the longitudinal associations with receptive vocabulary knowledge, joint engagement exhibited a significant concurrent association with infant cognitive ability (Bayley MDI scores). Infant cognitive ability, in turn, had a direct association with vocabulary knowledge at each of the three time points. We interpreted this relation as reciprocal, given that joint engagement is thought to promote infants' cognitive, social-emotional, and communicative skills and vice versa (Adamson et al., 2019; Yu et al., 2019). Notably, joint engagement also had a significant negative covariance with the latent variable negative interaction, consisting of measures of parent intrusiveness, parent negative regard toward the child, and child negativity taken from the 3-bag task. Previous research indicated that parental support and responsiveness to infants were associated with advances in children's language development (Tamis-LeMonda et al., 2001) whereas parental negativity towards the child was associated with delays in language development (Laake \& Bridgett, 2018). However, in our models there was no direct effect of negative interaction on vocabulary knowledge outcomes at any time point. Thus, intrusive parenting behaviors and negativity on the part of the parent towards the child appeared to influence later outcomes only by diminishing opportunities for joint engagement.

The observed relations were not only stable across time, but also relatively similar for both Black/African American and White/European American subgroups. The results of the measurement invariance provided some evidence of either metric invariance (for the latent variable joint engagement) or scalar invariance (for the latent variables negative interaction and maternal distress) between constructs. Given that assumptions of strict invariance failed, this suggests improvements could be made to ensure that measures used on a nationally 
DIRECT INDIRECT INFLUENCES VOCABULARY DEVELOPMENT

representative sample are culturally neutral. The differences in factor loadings of the negative interaction variable between groups, in particular, could point towards cultural differences that complicate the measurement of the construct (Pungello et al., 2009).

\section{Implications}

The present findings hold several important implications for improving vocabulary development of children reared in low SES contexts. Numerous past interventions have focused on improving the qualities of parent-child interactions to promote language development in children with language delays (Roberts \& Kaiser, 2011; Roberts et al., 2019). Vocabulary learning interventions for children from low-income households that are administered by parents have been shown to be as effective as those administered by teachers or researchers, and more effective than those administered by non-certified or non-degreed childcare providers (Marulis \& Neuman, 2013).

Other parent-child interactions have concentrated on dialogic reading among children between the ages of 3 and 5 (Troseth et al., 2020). However, such interventions tend to examine a broader range of behaviors and outcomes rather than specifically concentrating on vocabulary development during infancy and early childhood. Intervention studies designed to promote parent-child sustained attention and joint engagement behaviors associated with vocabulary development during a semi-structured play task suggest that it can be improved over time (Girolametto et al., 1994; McGillion et al., 2017; Suskind et al., 2016). Yet, whether behaviors associated with joint engagement either transfer to novel contexts (Girolametto et al., 1994) or persist over an extended period beyond several months from the initial training (McGillion et al., 2017; Suskind et al., 2016) remains undetermined. Further research should examine long-term effects of interventions designed to improve the quality of parent-child joint engagement, 
DIRECT INDIRECT INFLUENCES VOCABULARY DEVELOPMENT

particularly among parents and children from low SES households. If such behaviors are indeed malleable, the findings here suggest that the effects of the interventions could promote vocabulary development among children, including those of diverse backgrounds.

\section{Limitations}

While the findings appeared to be generally robust across both subgroups, there are several important limitations. First, even though many of the variables used in SEM were standardized measures, we were only able to establish measurement invariance of latent constructs at the metric or scalar level. Invariance at the level of the metric model was achieved for joint engagement, but at the more constrained level of the scalar model for negative interaction and maternal distress. Joint engagement and negative interaction were assessed via a single, relatively brief observation of mother-infant interaction (3-bag task). The measures might be more robust if based on observations taken more than once.

Second, examining differences in parent-child relationships as a function of population subgroups can be problematic as it may oversimplify complicated socio-cultural interactions (Dixon et al., 2008). For one, the present findings do not adequately take into consideration differences in children's dialect and how this affects the measurement of vocabulary knowledge based on standardized instruments such as the PPVT that are normed with speakers of standard American English dialects (Pearson et al., 2014). Past research has found that children with higher levels of non-standard dialect usage (i.e., African American English) tend to have more difficulty understanding words in standard American English (Edwards et al., 2014). Hence, standardized tests like the PPVT may potentially underestimate the vocabulary knowledge of Black/African American children as compared to White/European American children who speak only the standard dialect. Ideally, future studies should include multiple measures of children's 
DIRECT INDIRECT INFLUENCES VOCABULARY DEVELOPMENT

language development that extend beyond standardized tests of receptive vocabulary knowledge. This would ideally include taking natural language samples, which provide indices of utterance length, complexity, narrative skills, perspective-taking, imitation, and other facets of communicative development.

\section{Conclusions}

This study used SEM to determine pathways through which individual differences in receptive vocabulary trajectories emerge. We found that even after accounting for the influence of developmental factors of the child, parent, and home environment, mother-infant joint engagement had robust associations with the child's subsequent receptive vocabulary development through Grade 5 (approximate age 10 years). Furthermore, we found that associations were stable across Black/African American and White/European American subgroups that differed in socioeconomic risk, despite all families being of low income. The findings indicate how the positive impact of supportive parent-child interactions and home environments during infancy persist over time, and partially mediate indirect influences of maternal distress and maternal education on vocabulary growth. Given the robustness of results across time points and subgroups, the present findings serve to identify critical targets for early intervention to support and assist low-income mothers and their infants. 


\section{References}

AUTHOR. (2018).

AUTHOR. (2020).

AUTHOR. (2021). https://osf.io/8szqc/?view_only=161c0ec2cff649c88059bd499914bf5f

Abidin, R. R. (1995). Manual for the parenting stress index. Psychological Assessment Resources.

Acock, A. C. (2012). What to do about missing values. In H. Cooper, P. M. Camic, D. L. Long, A. T. Panter, D. Rindskopf, \& K. J. Sher (Eds.), APA handbook of research methods in psychology, Vol. 3. Data analysis and research publication (pp. 27-50). American Psychological Association.

Adamson, L. B. (2014). Joint attention and language development. In P. J. Brooks \& V. Kempe (Eds.), Encyclopedia of Language Development (pp. 299-303). Sage Publications.

Adamson, L. B., Bakeman, R., Suma, K., \& Robins, D. L. (2019). An expanded view of joint attention: Skill, engagement, and language in typical development and autism. Child Development, 90(1), e1-e18.

Ahun, M. N., Geoffroy, M. C., Herba, C. M., Brendgen, M., Séguin, J. R., Sutter-Dallay, A. L., ... \& Côté, S. M. (2017). Timing and chronicity of maternal depression symptoms and children's verbal abilities. The Journal of Pediatrics, 190, 251-257. doi:10.1016/j.jpeds.2017.07.007

Bakeman, R., \& Adamson, L. B. (1984). Coordinating attention to people and objects in mother-infant and peer-infant interaction. Child Development, 55(4), 1278-1289. doi:10.2307/1129997

Bayley, N. (1993). Bayley scales of infant development (BSID-II). Hartcourt Brace \& Company.

Bee, H. L., Barnard, K. E., Eyres, S. J., Gray, C. A., Hammond, M. A., Spietz, A. L., ... \& Clark, B. (1982). Prediction of IQ and language skill from perinatal status, child performance, family characteristics, and mother-infant interaction. Child Development, 1134-1156. doi: $10.2307 / 1129003$

Bhutta, A. T., Cleves, M. A., Casey, P. H., Cradock, M. M., \& Anand, K. J. S. (2002). Cognitive and behavioral outcomes of school-aged children who were born preterm: A meta-analysis. JAMA, 288(6), 728-737. doi:10.1001/jama.288.6.728 


\section{DIRECT INDIRECT INFLUENCES VOCABULARY DEVELOPMENT}

Bornstein, M. H., Cote, L. R., Maital, S., Painter, K., Park, S. Y., Pascual, L., ... \& Vyt, A. (2004). Cross-linguistic analysis of vocabulary in young children: Spanish, Dutch, French, Hebrew, Italian, Korean, and American English. Child Development, 75(4), 1115-1139. doi:10.1111/j.1467-8624.2004.00729.x

Bradley, R. H., Corwyn, R. F., Burchinal, M., McAdoo, H. P., \& García Coll, C. (2001). The home environments of children in the United States Part II: Relations with behavioral development through age thirteen. Child Development, 72(6), 1868-1886. doi:10.1111/1467-8624.t01-1-00382

Brooks-Gunn, J. \& Markman, L. B. (2005). The contribution of parenting to ethnic and racial gaps in school readiness. The Future of Children, 15(1), 139-168. https://www.jstor.org/stable/1602666

Brown, T. A. (2015). Confirmatory factor analysis for applied research (2nd Edition). Guilford Press.

Burchinal, M. R., Roberts, J. E., Hooper, S., \& Zeisel, S. A. (2000). Cumulative risk and early cognitive development: a comparison of statistical risk models. Developmental Psychology, 36(6), 793807. doi: $\underline{10.1037 / 0012-1649.36 .6 .793}$

Burchinal, M., Vernon-Feagans, L., Cox, M., \& Key Family Life Project Investigators. (2008). Cumulative social risk, parenting, and infant development in rural low-income communities. Parenting: Science and Practice, 8(1), 41-69. doi:10.1080/15295190701830672

Byrne, B. M., Shavelson, R. J., \& Muthén, B. (1989). Testing for the equivalence of factor covariance and mean structures: The issue of partial measurement invariance. Psychological Bulletin, 105(3), 456-466. doi:10.1037/0033-2909.105.3.456

Caldwell, B. \& Bradley, R. (1984). Home Observation for Measurement of the Environment (HOME) Revised Edition. University of Arkansas, Little Rock.

Carpenter, M., Nagell, K., \& Tomasello, M. (1998). Social cognition, joint attention, and communicative competence from 9 to 15 months of age. Monographs of the Society for Research in Child Development, 63(4), i-174. doi:10.2307/1166214 


\section{DIRECT INDIRECT INFLUENCES VOCABULARY DEVELOPMENT}

Ceballo, R., Chao, R., Hill, N. E., Le, H. N., Murry, V. M., \& Pinderhughes a, E. E. (2008). Excavating culture: Summary of results. Applied Development Science, 12(4), 220-226. doi: $\underline{10.1080 / 10888690802388110}$

Çetinçelik, M., Rowland, C. F., \& Snijders, T. M. (2021). Do the eyes have it? A systematic review on the role of eye gaze in infant language development. Frontiers in Psychology, 11, 3627. doi:10.3389/fpsyg.2020.589096

Charman, T., Baron-Cohen, S., Swettenham, J., Baird, G., Cox, A., \& Drew, A. (2000). Testing joint attention, imitation, and play as infancy precursors to language and theory of mind. Cognitive Development, 15(4), 481-498. doi:10.1016/S0885-2014(01)00037-5

Cheung, G. W., \& Rensvold, R. B. (2002). Evaluating goodness-of-fit indexes for testing measurement invariance. Structural Equation Modeling, 9(2), 233-255. doi:10.1207/S15328007SEM0902_5

Christian, K., Morrison, F. J., \& Bryant, F. B. (1998). Predicting kindergarten academic skills: Interactions among child care, maternal education, and family literacy environments. Early Childhood Research Quarterly, 13(3), 501-521. doi:10.1016/S0885-2006(99)80054-4

Davis-Kean, P. E. (2005). The influence of parent education and family income on child achievement: the indirect role of parental expectations and the home environment. Journal of Family Psychology, 19(2), 294-304. doi:10.1037/0893-3200.19.2.294

Day, A. (1986). Good dog, Carl. Simon \& Schuster.

Dixon, S. V., Graber, J. A., \& Brooks-Gunn, J. (2008). The roles of respect for parental authority and parenting practices in parent-child conflict among African American, Latino, and European American families. Journal of Family Psychology, 22(1), 1-10. doi:10.1037/0893-3200.22.1.1

Dollaghan, C. A., Campbell, T. F., Paradise, J. L., Feldman, H. M., Janosky, J. E., Pitcairn, D. N., \& Kurs-Lasky, M. (1999). Maternal education and measures of early speech and language. Journal of Speech, Language, and Hearing Research, 42(6), 1432-1443. doi:10.1044/jslhr.4206.1432

Duckworth, K., \& Sabates, R. (2005). Effects of mothers' education on parenting: an investigation across three generations. London Review of Education, 3(3), 239-264. doi:10.1080/14748460500372481 


\section{DIRECT INDIRECT INFLUENCES VOCABULARY DEVELOPMENT}

Duncan, G. J., \& Magnuson, K. (2012). Socioeconomic status and cognitive functioning: moving from correlation to causation. Wiley Interdisciplinary Reviews: Cognitive Science, 3(3), 377-386. doi: $10.1002 /$ wcs. 1176

Dunn, L. M., \& Dunn, L. M. (1997). Peabody Picture Vocabulary Test (3rd Ed.). American Guidance Service.

Edwards, J., Gross, M., Chen, J., MacDonald, M. C., Kaplan, D., Brown, M., \& Seidenberg, M. S. (2014). Dialect awareness and lexical comprehension of mainstream American English in African American English-speaking children. Journal of Speech, Language, and Hearing Research, 57(5), 1883-1895. doi:10.1044/2014 JSLHR-L-13-0228

Ensminger, M. E., Fothergill, K. E., Bornstein, M. H., \& Bradley, R. H. (2003). A decade of measuring SES: What it tells us and where to go from here. In M. H. Bornstein \& R. H. Bradley (Eds.), Socioeconomic status, parenting, and child development (pp. 13-27). Erlbaum.

Evans, G. W., Li, D., \& Whipple, S. S. (2013). Cumulative risk and child development. Psychological Bulletin, 139(6), 1342-1396. doi:10.1037/a0031808

Farah, M. J., Shera, D. M., Savage, J. H., Betancourt, L., Giannetta, J. M., Brodsky, N. L., ... \& Hurt, H. (2006). Childhood poverty: Specific associations with neurocognitive development. Brain Research, 1110(1), 166-174. doi:10.1016/j.brainres.2006.06.072

Flouri, E., \& Kallis, C. (2007). Adverse life events and psychopathology and prosocial behavior in late adolescence: testing the timing, specificity, accumulation, gradient, and moderation of contextual risk. Journal of the American Academy of Child \& Adolescent Psychiatry, 46(12), 1651-1659. doi:10.1097/chi.0b013e318156a81a

Fuligni, A. S., \& Brooks-Gunn, J. (2013). Mother-child interactions in Early Head Start: Age and ethnic differences in low-income dyads. Parenting, 13(1), 1-26. doi:10.1080/15295192.2013.732422

Girolametto, L., Verbey, M., \& Tannock, R. (1994). Improving joint engagement in parent-child interaction: An intervention study. Journal of Early Intervention, 18(2), 155-167. doi: $10.1177 / 105381519401800204$ 


\section{DIRECT INDIRECT INFLUENCES VOCABULARY DEVELOPMENT}

Guenole, N., \& Brown, A. (2014). The consequences of ignoring measurement invariance for path coefficients in structural equation models. Frontiers in Psychology, 5, 980.

doi: $10.3389 /$ fpsyg. 2014.00980

Guryan, J., Hurst, E., \& Kearney, M. (2008). Parental education and parental time with children. Journal of Economic Perspectives, 22(3), 23-46. doi:10.1257/jep.22.3.23

Hackman, D. A., Gallop, R., Evans, G. W., \& Farah, M. J. (2015). Socioeconomic status and executive function: Developmental trajectories and mediation. Developmental Science, 18(5), 686-702. doi: $\underline{10.1111 / \text { desc. } 12246}$

Hart, B., \& Risley, T. R. (1995). Meaningful differences in the everyday experiences of young American children. Paul H. Brookes.

Hill, N. E. (2001). Parenting and academic socialization as they relate to school readiness: The roles of ethnicity and family income. Journal of Educational Psychology, 93(4), 686-697. doi: $\underline{10.1037 / 0022-0663.93 .4 .686}$

Hill, N. E., \& Tyson, D. F. (2008). Excavating culture: Ethnicity and context as predictors of parenting behavior. Applied Development Science, 12(4), 188-197. doi:10.1080/10888690802388110

Hirsh-Pasek, K., Adamson, L. B., Bakeman, R., Owen, M. T., Golinkoff, R. M., Pace, A., ... \& Suma, K. (2015). The contribution of early communication quality to low-income children's language success. Psychological Science, 26(7), 1071-1083. doi:10.1177/0956797615581493

Hoff, E. (2003). The specificity of environmental influence: Socioeconomic status affects early vocabulary development via maternal speech. Child Development, 74(5), 1368-1378. doi: $\underline{10.1111 / 1467-8624.00612}$

Hsiao, Y. Y., \& Lai, M. H. (2018). The impact of partial measurement invariance on testing moderation for single and multi-level data. Frontiers in Psychology, 9, 740. doi:10.3389/fpsyg.2018.00740

Hu, L., \& Bentler, P. M. (1999). Cutoff criteria for fit indexes in covariance structure analysis: Conventional criteria versus new alternatives. Structural Equation Modeling, 6(1), 1-55. doi: $\underline{10.1080 / 10705519909540118}$ 


\section{DIRECT INDIRECT INFLUENCES VOCABULARY DEVELOPMENT}

Johnson, K., Caskey, M., Rand, K., Tucker, R., \& Vohr, B. (2014). Gender differences in adult-infant communication in the first months of life. Pediatrics, 134(6), e1603-e1610. doi:10.1542/peds.2013-4289

Jöreskog, K. G. (1971). Statistical analysis of sets of congeneric tests. Psychometrika, 36(2), 109-133. doi:10.1007/BF02291393

Jöreskog, K. G. (1993). Testing structural equation models. Sage Focus Editions, 154, 294-294.

Laake, L. M., \& Bridgett, D. J. (2018). Early language development in context: Interactions between infant temperament and parenting characteristics. Early Education and Development, 1-17. doi: $\underline{10.1080 / 10409289.2018 .1436366}$

Lebel, C., Walton, M., Letourneau, N., Giesbrecht, G. F., Kaplan, B. J., \& Dewey, D. (2016). Prepartum and postpartum maternal depressive symptoms are related to children's brain structure in preschool. Biological Psychiatry, 80(11), 859-868. doi:10.1016/j.biopsych.2015.12.004

Letourneau, N. L., Duffett-Leger, L., Levac, L., Watson, B., \& Young-Morris, C. (2013). Socioeconomic status and child development: A meta-analysis. Journal of Emotional and Behavioral Disorders, 21(3), 211-224. doi:10.1177/1063426611421007

Letourneau, N. L., Tramonte, L., \& Willms, J. D. (2013). Maternal depression, family functioning and children's longitudinal development. Journal of Pediatric Nursing, 28(3), 223-234. doi:10.1016/j.pedn.2012.07.014

Little, T. D. (2013). Longitudinal structural equation modeling. Guilford Press.

Little, E. E., Carver, L. J., \& Legare, C. H. (2016). Cultural variation in triadic infant-caregiver object exploration. Child Development, 87(4), 1130-1145. doi:10.1111/cdev.12513

Lovas, G. S. (2011). Gender and patterns of language development in mother-toddler and father-toddler dyads. First Language, 31(1), 83-108. doi:10.1177/0142723709359241

Love, J. M., Kisker, E. E., Ross, C., Raikes, H., Constantine, J., Boller, K., ... \& Fuligni, A. S. (2005). The effectiveness of early head start for 3-year-old children and their parents: Lessons for policy and programs. Developmental Psychology, 41(6), 885-901. doi:10.1037/0012-1649.41.6.88 


\section{DIRECT INDIRECT INFLUENCES VOCABULARY DEVELOPMENT}

Magnuson, K. A., Sexton, H. R., Davis-Kean, P. E., \& Huston, A. C. (2009). Increases in maternal education and young children's language skills. Merrill-Palmer Quarterly, 319-350. Retrieved from: https://www.jstor.org/stable/23096260

Marulis, L. M., \& Neuman, S. B. (2013). How vocabulary interventions affect young children at risk: A meta-analytic review. Journal of Research on Educational Effectiveness, 6(3), 223-262. doi: $\underline{10.1080 / 19345747.2012 .755591}$

Masarik, A. S., \& Conger, R. D. (2017). Stress and child development: A review of the Family Stress Model. Current Opinion in Psychology, 13, 85-90. doi:10.1016/j.copsyc.2016.05.008

Masek, L. R., McMillan, B. T., Paterson, S. J., Tamis-LeMonda, C. S., Golinkoff, R. M., \& Hirsh-Pasek, K. (2021). Where language meets attention: How contingent interactions promote learning. Developmental Review, 60, 100961. doi:10.1016/j.dr.2021.100961

McGillion, M., Pine, J. M., Herbert, J. S., \& Matthews, D. (2017). A randomised controlled trial to test the effect of promoting caregiver contingent talk on language development in infants from diverse socioeconomic status backgrounds. Journal of Child Psychology and Psychiatry, 58(10), 1122-1131. doi:10.1111/jcpp.12725

McLoyd, V. C. (1990). The impact of economic hardship on Black families and children: Psychological distress, parenting, and socioemotional development. Child Development, 61(2), 311-346. doi:10.1111/j.1467-8624.1990.tb02781.x

Melvin, S. A., Brito, N. H., Mack, L. J., Engelhardt, L. E., Fifer, W. P., Elliott, A. J., \& Noble, K. G. (2017). Home environment, but not socioeconomic status, is linked to differences in early phonetic perception ability. Infancy, 22(1), 42-55. doi: $\underline{10.1111 / \mathrm{infa} .12145}$

Merz, E. C., Wiltshire, C. A., \& Noble, K. G. (2019). Socioeconomic inequality and the developing brain: Spotlight on language and executive function. Child Development Perspectives, 13(1), 1520. doi:10.1111/cdep.12305 


\section{DIRECT INDIRECT INFLUENCES VOCABULARY DEVELOPMENT}

Milfont, T. L., \& Fischer, R. (2010). Testing measurement invariance across groups: Applications in cross-cultural research. International Journal of Psychological Research, 3(1), 111-130. doi: $10.21500 / 20112084.857$

NICHD Early Child Care Research Network. (1999). Child care and mother-child interaction in the first three years of life. Developmental Psychology, 35(6), 1399-1413. doi:10.1037/0012-

\section{$\underline{1649.35 .6 .1399}$}

Noble, K. G., Houston, S. M., Brito, N. H., Bartsch, H., Kan, E., Kuperman, J. M., ... \& Schork, N. J. (2015). Family income, parental education and brain structure in children and adolescents. Nature Neuroscience, 18(5), 773-778. doi:10.1038/nn.3983

Noel, M., Peterson, C., \& Jesso, B. (2008). The relationship of parenting stress and child temperament to language development among economically disadvantaged preschoolers. Journal of Child Language, 35(4), 823-843. doi:10.1017/S0305000908008805

Payne, A. C., Whitehurst, G. J., \& Angell, A. L. (1994). The role of home literacy environment in the development of language ability in preschool children from low-income families. Early Childhood Research Quarterly, 9(3-4), 427-440. doi:10.1016/0885-2006(94)90018-3

Pearson, B. Z., Jackson, J. E., \& Wu, H. (2014). Seeking a valid gold standard for an innovative, dialectneutral language test. Journal of Speech, Language, and Hearing Research, 57(2), 495-508. doi:10.1044/2013_JSLHR-L-12-0126

Pearson, R. M., Bornstein, M. H., Cordero, M., Scerif, G., Mahedy, L., Evans, J., ... \& Stein, A. (2016). Maternal perinatal mental health and offspring academic achievement at age 16: The mediating role of childhood executive function. Journal of Child Psychology and Psychiatry, 57(4), 491501. doi: $10.1111 /$ jepp.12483

Pinderhughes, E. E., Hurley, S., \& Conduct Problems Prevention Research Group. (2008). Disentangling ethnic and contextual influences among parents raising youth in high-risk communities. Applied Development Science, 12(4), 211-219. doi: $\underline{10.1080 / 10888690802388151}$ 


\section{DIRECT INDIRECT INFLUENCES VOCABULARY DEVELOPMENT}

Poulakos, A. (2013). Language development in context: Influences of perinatal risk and environmental characteristics on outcomes at 14 to 36 months (Doctoral Dissertation). Order No. 3601689. Available from ProQuest Dissertations \& Theses Global (1467526239).

Pungello, E. P., Iruka, I. U., Dotterer, A. M., Mills-Koonce, R., \& Reznick, J. S. (2009). The effects of socioeconomic status, race, and parenting on language development in early childhood. Developmental Psychology, 45(2), 544-557. doi:10.1037/a0013917

Putnick, D. L., \& Bornstein, M. H. (2016). Measurement invariance conventions and reporting: The state of the art and future directions for psychological research. Developmental Review, 41, 71-90. doi:10.1016/j.dr.2016.06.004

R Core Team. (2019). A language and environment for statistical computing. Vienna, Austria: $R$ Foundation for Statistical Computing. Retrieved from: https://www.R-project.org.

Radloff, L. S. (1977). The CES-D scale: A self-report depression scale for research in the general population. Applied Psychological Measurement, 1(3), 385-401. doi: $10.1177 / 014662167700100306$

Raikes, H., Alexander Pan, B., Luze, G., Tamis-LeMonda, C. S., Brooks-Gunn, J., Constantine, J., ... \& Rodriguez, E. T. (2006). Mother-child bookreading in low-income families: Correlates and outcomes during the first three years of life. Child Development, 77(4), 924-953. doi:10.1111/j.1467-8624.2006.00911.x

Roberts, M. Y., Curtis, P. R., Sone, B. J., \& Hampton, L. H. (2019). Association of parent training with child language development: A systematic review and meta-analysis. JAMA Pediatrics, 173(7), 671-680. doi:10.1001/jamapediatrics.2019.1197

Rosseel, Y. (2012). Lavaan: An R package for structural equation modeling and more. Version 0.5-12 (BETA). Journal of Statistical Software, 48(2), 1-36.

Stjernqvist, K., \& Svenningsen, N. W. (1999). Ten-year follow-up of children born before 29 gestational weeks: health, cognitive development, behaviour and school achievement. Acta Paediatrica, 88(5), 557-562. doi:10.1111/j.1651-2227.1999.tb00175.x 
DIRECT INDIRECT INFLUENCES VOCABULARY DEVELOPMENT

Suarez-Rivera, C., Schatz, J. L., Herzberg, O., \& Tamis-LeMonda, C. S. (2022). Joint engagement in the home environment is frequent, multimodal, timely, and structured. Infancy. doi:10.1111/infa.12446

Sung, J., Fausto-Sterling, A., García Coll, C., \& Seifer, R. (2013). The dynamics of age and sex in the development of mother-infant vocal communication between 3 and 11 months. Infancy, 18(6), 1135-1158. doi: $\underline{10.1111 / \text { infa.12019 }}$

Suskind, D. L., Leffel, K. R., Graf, E., Hernandez, M. W., Gunderson, E. A., Sapolich, S. G., ... \& Levine, S. C. (2016). A parent-directed language intervention for children of low socioeconomic status: A randomized controlled pilot study. Journal of Child Language, 43(2), 366-406. doi: $10.1017 / \mathrm{S} 0305000915000033$

Tamis-LeMonda, C. S., Bornstein, M. H., \& Baumwell, L. (2001). Maternal responsiveness and children's achievement of language milestones. Child Development, 72(3), 748-767. doi: $\underline{10.1111 / 1467-8624.00313}$

Tomalski, P., Moore, D. G., Ribeiro, H., Axelsson, E. L., Murphy, E., Karmiloff-Smith, A., ... \& Kushnerenko, E. (2013). Socioeconomic status and functional brain development-associations in early infancy. Developmental Science, 16(5), 676-687. doi:10.1111/desc.12079

Troseth, G. L., Strouse, G. A., Flores, I., Stuckelman, Z. D., \& Johnson, C. R. (2020). An enhanced eBook facilitates parent-child talk during shared reading by families of low socioeconomic status. Early Childhood Research Quarterly, 50, 45-58. doi:10.1016/j.ecresq.2019.02.009

United States Department of Health and Human Services, Administration for Children and Families. (2011). Administration for Children and Families. (2011). Early Head Start Research and Evaluation (EHSRE) Study, 1996-2010: [United States]. ICPSR03804-v5. Ann Arbor, MI: Interuniversity Consortium for Political and Social Research [distributor], 09-22. https://www.icpsr.umich.edu/web/ICPSR/studies/3804/

United States Department of Health and Human Services, Administration for Children and Families. (2019a). Early Head Start Research and Evaluation Project (EHSRE), 1996-2010: Project 


\section{DIRECT INDIRECT INFLUENCES VOCABULARY DEVELOPMENT}

overview. U.S. Department of Health and Human Services.

https://www.acf.hhs.gov/opre/research/project/early-head-start-research-and-evaluation-project$\underline{\text { ehsre-1996-2010 }}$

United States Department of Health and Human Services, Administration for Children and Families. (2019b). EHSRE Videotaped Protocol Booklet-14 Months. U.S. Department of Health and Human Services. [Last reviewed 29 April 2019]. Retrieved from https://www.acf.hhs.gov/opre/resource/videotaped-protocol-booklet-14-months

Ursache, A., \& Noble, K. G. for the Pediatric Imaging, Neurocognition and Genetics Study. (2016). Socioeconomic status, white matter, and executive function in children. Brain and Behavior, 6(10), e00531. doi: $10.1002 / \mathrm{brb3} .531$

Van Buuren, S. \& Groothuis-Oudshoorn, K. (2011). mice: Multivariate Imputation by Chained Equations in R. Journal of Statistical Software, 45(3), 1-67. Retrieved from: https://www.jstatsoft.org/v45/i03/.

Vernon-Feagans, L., Bratsch-Hines, M., Reynolds, E., \& Willoughby, M. (2020). How early maternal language input varies by race and education and predicts later child language. Child Development, 91(4), 1098-1115. doi:10.1111/cdev.13281

Ware, A., Brady, C., O’Brien, C., \& Berlin, L. J. (2000). EHSRE 14-Month child-parent interaction rating scales for the Three Bag Assessment. National Center for Children and Families, Teachers College, Columbia University. Retrieved from: http://policyforchildren.org/wpcontent/uploads/2013/08/14mos_3bscales_final_62805.pdf

Yeung, W. J., \& Conley, D. (2008). Black-White achievement gap and family wealth. Child Development, 79, 303-324. doi:10.1111/j.1467-8624.2007.01127.x

Yu, C., Suanda, S. H., \& Smith, L. B. (2018). Infant sustained attention but not joint attention to objects at 9 months predicts vocabulary at 12 and 15 months. Developmental Science, 22(1), e12735. doi: $10.1111 /$ desc. 12735 
Zajicek-Farber, M. L. (2010). The contributions of parenting and postnatal depression on emergent language of children in low-income families. Journal of Child and Family Studies, 19(3), 257269. doi: $10.1007 / \mathrm{s} 10826-009-9293-7$ 
DIRECT INDIRECT INFLUENCES VOCABULARY DEVELOPMENT

\section{Supplemental Materials}

\section{Table S1}

List of variables used

\begin{tabular}{|c|c|c|c|c|c|}
\hline Age & $\begin{array}{l}\text { Domain } \\
\text { (as referenced in } \\
\text { manuscript) }\end{array}$ & $\begin{array}{l}\text { Variable } \\
\text { Label } \\
\text { (from EHSRE } \\
\text { data set) }\end{array}$ & $\begin{array}{l}\text { Variable Name } \\
\text { (as referenced in } \\
\text { manuscript) }\end{array}$ & Measure & $\begin{array}{l}\text { Variable Derivation } \\
\text { (from EHSRE codebook) }\end{array}$ \\
\hline \multirow{7}{*}{14 months } & \multirow{5}{*}{ Demographics } & C_MALE & Focal child's gender & $\begin{array}{l}\text { Parental self-report } \\
\text { administered at baseline }\end{array}$ & $\begin{array}{l}\text { (0) Female } \\
\text { (1) Male } \\
-5-5 / . E=\text { missing item }\end{array}$ \\
\hline & & $\begin{array}{l}\text { FC_BRN } \\
\text { (recoded*) }\end{array}$ & $\begin{array}{l}\text { Focal child gestational } \\
\text { length (recoded to } \\
\text { indicate if focal child was } \\
\text { born premature or not.) }\end{array}$ & $\begin{array}{l}\text { Parental self-report } \\
\text { administered at baseline }\end{array}$ & $\begin{array}{l}\text { (1) More than } 2 \text { months early } \\
\text { (2) } 2 \text { months to } 3 \text { weeks early } \\
\text { (3) About on time } \\
\text { (4) More than } 3 \text { weeks late } \\
-6-6 / . \mathrm{F}=\text { missingSectn } \\
-5-5 / . \mathrm{E}=\text { missing item } \\
-1-1 / . \mathrm{A}=\mathrm{DK} \\
\text { * Recoded such that if the child was born premature (1) or not }(0)\end{array}$ \\
\hline & & ENGLISH & $\begin{array}{l}\text { Primary caregiver's } \\
\text { primary language is } \\
\text { English }\end{array}$ & $\begin{array}{l}\text { Parental self-report } \\
\text { administered at baseline }\end{array}$ & $\begin{array}{l}0(0) \text { Not English } \\
1(1) \text { English } \\
-6-6 / . \text { F=missingSectn } \\
-5-5 / . E=\text { =missing item }\end{array}$ \\
\hline & & HGCG & $\begin{array}{l}\text { Primary caregiver's } \\
\text { educational attainment }\end{array}$ & $\begin{array}{l}\text { Parental self-report } \\
\text { administered at baseline }\end{array}$ & $\begin{array}{l}\text { (1) Completed less than } 12 \text { years of schooling } \\
\text { (2) Completed } 12 \text { years of school or a GED } \\
\text { (3) Completed more than } 12 \text { years of schooling } \\
-6-6 / . \mathrm{F}=\text { missingSectn } \\
-5-5 / . \mathrm{E}=\text { missing item }\end{array}$ \\
\hline & & POVRATIO & $\begin{array}{l}\text { Income as \% of Poverty } \\
\text { line for family }\end{array}$ & $\begin{array}{l}\text { Parental self-report } \\
\text { administered at baseline }\end{array}$ & $\begin{array}{l}\text { Use year, household size and number of children in household to determine the } \\
\text { poverty line income (povline). If there is insufficient information to determine povline } \\
\text { or household income is missing, then set povratio to missing. Otherwise, set } \\
\text { povratio=household income multiplied by } 100 / \text { povline. If povratio is missing, then set } \\
\text { povgroup to missing. Otherwise, if } 0<=\text { povratio }<33 \text {, then set povgroup }=1 \text {. Otherwise, } \\
\text { if } 33<=\text { povratio }<67 \text {, then set povgroup }=2 \text {. Otherwise, if } 67<=\text { povratio }<100 \text {, then set } \\
\text { povgroup }\end{array}$ \\
\hline & Infant Cognition & B1B_MDI & Infant Cognition & Bayley MDI Score & $\begin{array}{l}\text { The Bayley MDI was normed on a nationally representative sample of children of } \\
\text { various ages so that raw scores can be converted to age-adjusted, standardized scores } \\
\text { with a mean of } 100 \text { and a standard deviation of } 15 \text {. BnB_MDI (where } n=1,2,3 \text { is a } \\
\text { birthday-related time period). }\end{array}$ \\
\hline & $\begin{array}{c}\text { Home } \\
\text { Environment }\end{array}$ & B1P_HOME & Home Environment & $\begin{array}{l}\text { HOME Environment Total } \\
\text { Score }\end{array}$ & $\begin{array}{l}\text { Measures the cognitive stimulation and emotional support provided by the parent in } \\
\text { the home environment. Information needed to score the inventory is obtained through } \\
\text { a combination of interview and observation conducted in the home with the child's } \\
\text { parent while the child is present. The total includes all of the } 31 \text { items included in } 5 \\
\text { subscales (including one that was dropped) out of the original } 45 \text { items. The } \\
\text { maximum potential score is } 31 \text {. }\end{array}$ \\
\hline
\end{tabular}


DIRECT INDIRECT INFLUENCES VOCABULARY DEVELOPMENT

\begin{tabular}{|c|c|c|c|c|c|}
\hline Age & $\begin{array}{l}\text { Domain } \\
\text { (as referenced in } \\
\text { manuscript) }\end{array}$ & $\begin{array}{l}\text { Variable } \\
\text { Label } \\
\text { (from EHSRE } \\
\text { data set) }\end{array}$ & $\begin{array}{l}\text { Variable Name } \\
\text { (as referenced in } \\
\text { manuscript) }\end{array}$ & Measure & $\begin{array}{l}\text { Variable Derivation } \\
\text { (from EHSRE codebook) }\end{array}$ \\
\hline \multirow{9}{*}{14 months } & \multirow{3}{*}{$\begin{array}{c}\text { Joint } \\
\text { Engagement }\end{array}$} & B1V3_SUP & Parent Supportiveness & 3-bag & $\begin{array}{l}\text { Parent Behavior during Parent-Child Semistructured Play - measures the parents } \\
\text { behavior with the child during a semistructured play task. The parent and child were } \\
\text { given three bags of interesting toys and asked to play with the toys in sequence. The } \\
\text { semistructured play task was videotaped, and child and parent behaviors were coded } \\
\text { by child development researchers according to strict protocols }\end{array}$ \\
\hline & & B1V3CENG & $\begin{array}{l}\text { Child Engagement of } \\
\text { Parent }\end{array}$ & 3-bag & r \\
\hline & & B1V3CATN & $\begin{array}{l}\text { Child Sustained Attention } \\
\text { with Objects }\end{array}$ & 3-bag & - \\
\hline & \multirow{3}{*}{ Negative } & BnV3PINT & Parent Intrusiveness & 3-bag & - \\
\hline & & B1V3PNEG & $\begin{array}{l}\text { Parent Negative Regard } \\
\text { toward Child }\end{array}$ & 3-bag & - \\
\hline & & B1V3CNEG & $\begin{array}{l}\text { Child Negativity Toward } \\
\text { Parent } \\
\end{array}$ & 3-bag & - \\
\hline & \multirow{3}{*}{ Maternal Distress } & B1P_PD & Parental Distress & $\begin{array}{l}\text { Parental Distress Scale } \\
\quad \text { (Abidin, 1995) }\end{array}$ & $\begin{array}{l}\text { Parenting Stress Index -- Short Form (PSI-SF) -- measures the degree of stress in } \\
\text { parent-child relationships stemming from three possible sources: the childs } \\
\text { challenging temperament, parental depression, and negatively reinforcing parent-child } \\
\text { interactions (Abidin 1995). Parental Distress measures the level of distress the parent } \\
\text { is feeling in his or her role as a parent stemming from personal factors, including a } \\
\text { low sense of competence as a parent, stress because of perceived restrictions } \\
\text { stemming from parenting, depression, and lack of social support. The parent answers } \\
\text { whether he or she agrees or disagrees with statements such as, "You often have the } \\
\text { feeling that you cannot handle things very well," and "You feel trapped by your } \\
\text { responsibilities as a parent," and "You feel alone and without friends." Item responses } \\
\text { were coded on a 5-point scale (initially, } 1=\mathrm{SA}, 2=\mathrm{A}, 3=\mathrm{DK}, 4=\mathrm{D}, 5=\mathrm{SD} \text {, recoded } \\
\text { to } 5=\text { Strongly Agree, } 4=\text { Agree, } 3=\mathrm{DK}, 2=\mathrm{Disagree}, 1=\mathrm{Strongly} \text { Disagree), so that } \\
5 \text { indicates high levels of [TYPE]. Define BnP_[TYPE] as the sum of the } 12 \text { recoded } \\
\text { items, [LIST], using imputed values if one or two of the items were missing. Scores } \\
\text { on the } 12 \text {-item subscale can range from } 12 \text { to } 60 \text {. }\end{array}$ \\
\hline & & B1P_PCDI & $\begin{array}{c}\text { Parent-Child } \\
\text { Dysfunctional Interaction }\end{array}$ & $\begin{array}{l}\text { Parental Distress Scale } \\
\quad \text { (Abidin, 1995) }\end{array}$ & $\begin{array}{l}\text { Parenting Stress Index -- Short Form (PSI-SF) -- measures the degree of stress in } \\
\text { parent-child relationships stemming from three possible sources: the childs } \\
\text { challenging temperament, parental depression, and negatively reinforcing parent-child } \\
\text { interactions (Abidin 1995). The parent may perceive that the child is abusing or } \\
\text { rejecting the parent or that the parent feels disappointed in or alienated from the child. } \\
\text { The parent answers whether he or she agrees or disagrees with statements such as, } \\
\text { "Your child rarely does things for you that make you feel good," and "Most times you } \\
\text { feel that your child does not like you and does not want to be close to you," and "Your } \\
\text { child seems to smile less than most children." Item responses were coded on a 5-point } \\
\text { scale (initially, } 1=\text { SA, } 2=\text { A, } 3=\text { DK, } 4=D, 5=\text { SD, recoded to } 5=\text { Strongly Agree, } 4 \\
\text { = Agree, } 3=\text { DK, } 2=\text { Disagree, } 1=\text { Strongly Disagree), so that } 5 \text { indicates high levels } \\
\text { of [TYPE]. Define BnP_[TYPE] as the sum of the } 12 \text { recoded items, [LIST], using } \\
\text { imputed values if one or two of the items were missing. Scores on the } 12 \text {-item } \\
\text { subscale can range from } 12 \text { to } 60 \text {. }\end{array}$ \\
\hline & & B1P_CESD & $\begin{array}{l}\text { Parental Depressive } \\
\text { Symptoms }\end{array}$ & $\begin{array}{l}\text { CES-Depression Scale } \\
\text { Total Score } \\
\end{array}$ & $\begin{array}{l}\text { The Long Form ( } 20 \text { items) CES-D was administered at } 14 \text { months. "Long form" } \\
\text { scores were computed from all } 20 \text { items at baseline and } 14 \text { months. }\end{array}$ \\
\hline
\end{tabular}

Supplemental Materials - 49 
DIRECT INDIRECT INFLUENCES VOCABULARY DEVELOPMENT

\begin{tabular}{|c|c|c|c|c|c|}
\hline Age & $\begin{array}{l}\text { Domain } \\
\text { (as referenced in } \\
\text { manuscript) }\end{array}$ & $\begin{array}{c}\text { Variable } \\
\text { Label } \\
\text { (from EHSRE } \\
\text { data set) }\end{array}$ & $\begin{array}{l}\text { Variable Name } \\
\text { (as referenced in } \\
\text { manuscript) }\end{array}$ & Measure & $\begin{array}{c}\text { Variable Derivation } \\
\text { (from EHSRE codebook) }\end{array}$ \\
\hline 14 months & $\begin{array}{l}\text { Vocabulary } \\
\text { Knowledge }\end{array}$ & B1P_VPRD & Vocabulary Knowledge & $\begin{array}{l}\text { MacArthur CDI } \\
\text { Vocabulary Production } \\
\text { Score }\end{array}$ & $\begin{array}{l}\text { The MacArthur CDI measure was either completed by an interviewer with the parent } \\
\text { or by the parent themselves. A sum score was derived reflecting the total number of } \\
\text { words the child had produced at age } 14 \text { months. }\end{array}$ \\
\hline 36 months & $\begin{array}{l}\text { Vocabulary } \\
\text { Knowledge }\end{array}$ & B3RPPVTS & Vocabulary Knowledge & PPVT-III Standard Score & $\begin{array}{l}\text { The child is presented with four pictures and is asked to point to the picture that } \\
\text { matches the word spoken by the interviewer. The PPVT-III was normed on a } \\
\text { nationally representative sample of children and adults of various ages so that raw } \\
\text { scores can be converted to age-adjusted, standardized scores with a mean of } 100 \text { and a } \\
\text { standard deviation of } 15 \text {. }\end{array}$ \\
\hline Pre K & $\begin{array}{l}\text { Vocabulary } \\
\text { Knowledge }\end{array}$ & C4PPVT3S & Vocabulary Knowledge & PPVT-III Standard Score & 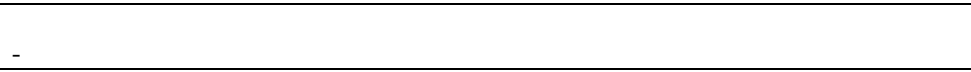 \\
\hline Grade 5 & $\begin{array}{l}\text { Vocabulary } \\
\text { Knowledge }\end{array}$ & C5PPVT3S & Vocabulary Knowledge & PPVT-III Standard Score & - \\
\hline
\end{tabular}


DIRECT INDIRECT INFLUENCES VOCABULARY DEVELOPMENT

Table S2

Correlations between 14-month predictors and vocabulary outcomes

\begin{tabular}{|c|c|c|c|c|c|c|c|c|c|c|c|c|c|c|}
\hline & 1. & 2. & 3. & 4. & 5. & 6. & 7. & 8. & 9. & 10. & 11. & 12. & 13. & 14. \\
\hline 1. Bayley MDI & - & 0.002 & $<.001$ & $<.001$ & $<.001$ & 0.001 & 0.026 & 0.042 & 0.898 & 0.732 & 0.085 & $<.001$ & $<.001$ & $<.001$ \\
\hline 2. HOME Inventory & 0.15 & - & $<.001$ & $<.001$ & $<.001$ & $<.001$ & $<.001$ & 0.010 & $<.001$ & $<.001$ & $<.001$ & $<.001$ & $<.001$ & $<.001$ \\
\hline \multicolumn{15}{|l|}{ 3-bag Task } \\
\hline 3. Parent Supportiveness & 0.18 & 0.48 & - & $<.001$ & $<.001$ & $<.001$ & $<.001$ & $<.001$ & 0.046 & 0.058 & $<.001$ & $<.001$ & $<.001$ & $<.001$ \\
\hline 4. Child Engagement of Parent & 0.18 & 0.19 & 0.49 & - & $<.001$ & 0.001 & $<.001$ & $<.001$ & 0.780 & 0.760 & 0.008 & $<.001$ & 0.003 & 0.003 \\
\hline 5. Child Sustained Attention & 0.22 & 0.24 & 0.51 & 0.31 & - & $<.001$ & $<.001$ & $<.001$ & 0.678 & 0.096 & 0.002 & $<.001$ & $<.001$ & $<.001$ \\
\hline 6. Parent Intrusiveness & -0.17 & -0.22 & -0.37 & -0.15 & -0.40 & - & $<.001$ & $<.001$ & 0.338 & 0.591 & 0.035 & $<.001$ & $<.001$ & $<.001$ \\
\hline 7. Parent Negative Regard & -0.11 & -0.24 & -0.38 & -0.17 & -0.31 & 0.42 & - & $<.001$ & 0.989 & 0.363 & 0.001 & $<.001$ & $<.001$ & 0.012 \\
\hline 8. Child Negativity toward Parent & -0.10 & -0.12 & -0.30 & -0.19 & -0.38 & 0.63 & 0.29 & - & 0.805 & 0.705 & 0.166 & 0.002 & 0.029 & 0.002 \\
\hline \multicolumn{15}{|l|}{ Maternal Distress Variables } \\
\hline 9. CES-D Depression Scale & -0.01 & -0.21 & -0.10 & -0.01 & -0.02 & 0.05 & 0.00 & 0.01 & - & $<.001$ & $<.001$ & 0.133 & 0.012 & 0.010 \\
\hline 10. Parent Distress Inventory & 0.02 & -0.28 & -0.09 & -0.01 & -0.08 & 0.03 & 0.04 & 0.02 & 0.53 & - & $<.001$ & 0.001 & $<.001$ & 0.016 \\
\hline 11. Parent-Child Dysfunctional Interaction & -0.08 & -0.32 & -0.18 & -0.13 & -0.15 & 0.10 & 0.16 & 0.07 & 0.34 & 0.47 & - & 0.001 & $<.001$ & 0.001 \\
\hline \multicolumn{15}{|l|}{$P P V T$} \\
\hline 12. 36 months & 0.31 & 0.30 & 0.33 & 0.21 & 0.35 & -0.21 & -0.19 & -0.15 & -0.07 & -0.15 & -0.15 & - & $<.001$ & $<.001$ \\
\hline 13. Pre-K & 0.26 & 0.37 & 0.35 & 0.15 & 0.36 & -0.25 & -0.22 & -0.12 & -0.13 & -0.18 & -0.18 & 0.60 & - & $<.001$ \\
\hline 14. Grade 5 & 0.29 & 0.40 & 0.40 & 0.17 & 0.35 & -0.31 & -0.14 & -0.18 & -0.14 & -0.13 & -0.17 & 0.57 & 0.71 & - \\
\hline
\end{tabular}

Note: Values below the diagonal reflect Pearson correlation coefficients. Values above the diagonal reflect corresponding p-values. 
Table S3

Estimated marginal means (EMM) for measures at child age 14 months controlling for household income (POVRATIO) and maternal educational attainment (HGCG)

\begin{tabular}{|c|c|c|c|c|c|c|c|}
\hline \multirow[t]{2}{*}{ 14-month predictors } & \multicolumn{2}{|c|}{$\begin{array}{c}\text { Black/African } \\
\text { American }\end{array}$} & \multicolumn{2}{|c|}{$\begin{array}{c}\text { White/ European } \\
\text { American }\end{array}$} & \multirow[b]{2}{*}{$t$} & \multirow[b]{2}{*}{$p$} & \multirow[b]{2}{*}{$d$} \\
\hline & $N$ & $E M M(S D)$ & $N$ & $E M M(S D)$ & & & \\
\hline Bayley MDI & 173 & $97.8(9.8)$ & 253 & $99.2(16.6)$ & -1.03 & .305 & -.119 \\
\hline HOME Inventory & 201 & $26.0(3.5)$ & 272 & $27.3(3.1)$ & -4.45 & $<.001 * * *$ & -.480 \\
\hline \multicolumn{8}{|l|}{ 3-bag Task } \\
\hline Parent Supportiveness & 185 & $3.7(1.1)$ & 256 & $4.2(1.0)$ & -5.17 & $<.001 * * *$ & -.578 \\
\hline Child Engagement of Parent & 185 & $3.9(1.3)$ & 256 & $3.9(1.2)$ & -.11 & .916 & -.012 \\
\hline Child Sustained Attention & 185 & $4.7(1.2)$ & 256 & $5.2(1.0)$ & -4.61 & $<.001 * * *$ & -.514 \\
\hline Parent Intrusiveness & 185 & $2.8(1.4)$ & 256 & $2.1(1.2)$ & 5.11 & $<.001 * * *$ & .571 \\
\hline Parent Negative Regard & 185 & $1.6(0.8)$ & 256 & $1.3(0.7)$ & 4.33 & $<.001 * * *$ & .483 \\
\hline Child Negativity toward Parent & 185 & $2.3(1.3)$ & 256 & $1.9(1.1)$ & 3.46 & $<.001 * * *$ & .386 \\
\hline \multicolumn{8}{|l|}{ Maternal Distress Variables } \\
\hline CES-D Depression Scale & 218 & $12.6(11.4)$ & 278 & $14.2(10.1)$ & -1.57 & .117 & -.051 \\
\hline Parent Distress Inventory & 222 & $27.6(11.5)$ & 280 & $26.6(10.2)$ & 1.01 & .315 & .104 \\
\hline Parent-Child Dysfunctional Interaction & 222 & $17.4(6.9)$ & 280 & $17.0(6.1)$ & .66 & .511 & .068 \\
\hline
\end{tabular}


DIRECT INDIRECT INFLUENCES VOCABULARY DEVELOPMENT

Table S4

Estimated marginal means (EMM) for PPVT scores at child age 36 months, 4 years, and Grade 5 controlling for household income (POVRATIO) and maternal educational attainment (HGCG)

\begin{tabular}{|c|c|c|c|c|c|c|c|}
\hline \multirow[t]{2}{*}{ Age } & \multicolumn{2}{|c|}{$\begin{array}{c}\text { Black/African } \\
\text { American }\end{array}$} & \multicolumn{2}{|c|}{$\begin{array}{c}\text { White/ European } \\
\text { American }\end{array}$} & \multirow[b]{2}{*}{$t$} & \multirow[b]{2}{*}{$p$} & \multirow[b]{2}{*}{$d$} \\
\hline & $N$ & $E M M(S D)$ & $N$ & $E M M(S D)$ & & & \\
\hline 36 months & 247 & $79.6(18.5)$ & 309 & $86.2(16.2)$ & -4.39 & $<.001$ & -.434 \\
\hline Pre-K & 192 & $86.2(15.6)$ & 253 & $98.2(13.7)$ & -8.43 & $<.001$ & -.931 \\
\hline Grade 5 & 168 & $89.0(15.9)$ & 209 & $102.0(14.1)$ & -8.03 & $<.001$ & -.956 \\
\hline
\end{tabular}


Table S5

Standardized regression coefficients and predictors of children's receptive vocabulary knowledge (PPVT) at age 36 months, Pre-K (48 months), and grade 5 (approx. 120- months)

$36 \mathrm{~m} \quad$ Pre-K $\quad$ Grade 5

\begin{tabular}{|c|c|c|c|c|c|c|}
\hline & \multicolumn{2}{|c|}{$(N=357)$} & \multicolumn{2}{|c|}{$(N=292)$} & \multicolumn{2}{|c|}{$(N=251)$} \\
\hline Child Gender (1 = Male $)$ & -.17 & $* *$ & -.08 & & .01 & \\
\hline Child Gestational Age & .09 & . & .07 & & .06 & \\
\hline Home Language ( $1=$ English $)$ & -.01 & & -.08 & & -.04 & \\
\hline Maternal Education & .19 & $* * *$ & .18 & $* *$ & .20 & $* *$ \\
\hline Poverty Ratio & .01 & & .14 & $*$ & .05 & \\
\hline$R^{2}$ total (Adjusted $R^{2}$ ) & $.07(.05)$ & & $.08(.07)$ & & $.05(.04)$ & \\
\hline Model $F(5, N-8)$ & 5.13 & $* * *$ & 5.10 & $* * *$ & 2.83 & $*$ \\
\hline
\end{tabular}

$* * * p<.001, * * p<.01, * p<.05, \cdot p<.10$ 
Table S6

Standardized estimates for SEM predicting variation in children's receptive vocabulary knowledge (PPVT) at $36 \mathrm{~m}$ based on predictors measured at $14 \mathrm{~m}$.

\begin{tabular}{|c|c|c|c|c|c|c|c|c|c|c|c|c|}
\hline & \multicolumn{6}{|c|}{ Black/African American } & \multicolumn{6}{|c|}{ White/European American } \\
\hline & $\begin{array}{c}\text { Std. } \\
\text { Estimate } \\
(\beta)\end{array}$ & $S E$ & $\begin{array}{l}95 \% \text { CI } \\
\text { (Lower) }\end{array}$ & $\begin{array}{l}95 \% \text { CI } \\
\text { (Upper) }\end{array}$ & $z$ & $p$ & $\begin{array}{c}\text { Std. } \\
\text { Estimate } \\
(\beta)\end{array}$ & $S E$ & $\begin{array}{l}95 \% \text { CI } \\
\text { (Lower) }\end{array}$ & $\begin{array}{l}95 \% \text { CI } \\
\text { (Upper) }\end{array}$ & $z$ & $p$ \\
\hline \multicolumn{13}{|l|}{ Latent Variables } \\
\hline \multicolumn{13}{|l|}{ Joint Attention $=\sim$} \\
\hline Child Attention & 0.59 & 0.07 & 0.45 & 0.73 & 8.18 & $<.001$ & 0.52 & 0.08 & 0.36 & 0.69 & 6.26 & $<.001$ \\
\hline Parental Supportiveness & 0.82 & 0.08 & 0.67 & 0.97 & 10.61 & $<.001$ & 0.90 & 0.07 & 0.76 & 1.03 & 12.82 & $<.001$ \\
\hline Child Engagement of Parent & 0.57 & 0.07 & 0.42 & 0.71 & 7.82 & $<.001$ & 0.58 & 0.06 & 0.46 & 0.69 & 9.87 & $<.001$ \\
\hline \multicolumn{13}{|l|}{ Negative Interaction $=\sim$} \\
\hline Parental Intrusiveness & 0.93 & 0.09 & 0.76 & 1.10 & 10.83 & $<.001$ & 0.78 & 0.08 & 0.62 & 0.94 & 9.64 & $<.001$ \\
\hline Parental Negative Regard & 0.37 & 0.08 & 0.21 & 0.53 & 4.50 & $<.001$ & 0.54 & 0.08 & 0.38 & 0.69 & 6.76 & $<.001$ \\
\hline Child Negativity to Parent & 0.66 & 0.09 & 0.50 & 0.83 & 7.73 & $<.001$ & 0.76 & 0.08 & 0.60 & 0.92 & 9.58 & $<.001$ \\
\hline \multicolumn{13}{|l|}{ Maternal Distress = } \\
\hline Maternal Distress & 0.84 & 0.07 & 0.70 & 0.98 & 11.65 & $<.001$ & 0.77 & 0.06 & 0.66 & 0.88 & 13.49 & $<.001$ \\
\hline Parent-Child Dysfunction & 0.59 & 0.07 & 0.46 & 0.71 & 8.94 & $<.001$ & 0.60 & 0.07 & 0.46 & 0.74 & 8.38 & $<.001$ \\
\hline Parental Dep. Symptoms & 0.67 & 0.07 & 0.53 & 0.81 & 9.48 & $<.001$ & 0.63 & 0.06 & 0.51 & 0.74 & 10.74 & $<.001$ \\
\hline \multicolumn{13}{|l|}{ Regressions } \\
\hline \multicolumn{13}{|l|}{ HOME } \\
\hline Maternal Distress & -0.22 & 0.08 & -0.39 & -0.06 & -2.73 & 0.006 & -0.46 & 0.09 & -0.63 & -0.29 & -5.37 & $<.001$ \\
\hline Maternal Education & 0.29 & 0.06 & 0.19 & 0.40 & 5.29 & $<.001$ & 0.18 & 0.06 & 0.06 & 0.30 & 2.85 & 0.004 \\
\hline \multicolumn{13}{|l|}{ Negative Interaction } \\
\hline Maternal Education & -0.02 & 0.10 & -0.21 & 0.18 & -0.18 & 0.857 & -0.17 & 0.07 & -0.30 & -0.03 & -2.38 & 0.017 \\
\hline HOME & -0.16 & 0.11 & -0.36 & 0.05 & -1.49 & 0.136 & -0.09 & 0.10 & -0.30 & 0.11 & -0.92 & 0.355 \\
\hline \multicolumn{13}{|l|}{ Joint Attention } \\
\hline Maternal Education & 0.12 & 0.09 & -0.05 & 0.30 & 1.40 & 0.163 & 0.12 & 0.06 & -0.01 & 0.24 & 1.85 & 0.065 \\
\hline HOME & 0.41 & 0.12 & 0.17 & 0.65 & 3.33 & 0.001 & 0.42 & 0.11 & 0.20 & 0.65 & 3.70 & $<.001$ \\
\hline \multicolumn{13}{|l|}{ Child Cognition } \\
\hline Gestational Age & 0.27 & 0.09 & 0.10 & 0.44 & 3.14 & 0.002 & 0.13 & 0.07 & -0.01 & 0.27 & 1.81 & 0.071 \\
\hline Gender (1=male $)$ & -0.09 & 0.07 & -0.23 & 0.05 & -1.28 & 0.201 & -0.10 & 0.06 & -0.22 & 0.03 & -1.55 & 0.121 \\
\hline HOME & 0.13 & 0.08 & -0.03 & 0.29 & 1.54 & 0.124 & 0.14 & 0.06 & 0.03 & 0.25 & 2.51 & 0.012 \\
\hline \multicolumn{13}{|l|}{ Child Vocabulary $(36 \mathrm{~m}) \sim$} \\
\hline Gestational Age & 0.08 & 0.07 & -0.05 & 0.22 & 1.22 & 0.221 & -0.01 & 0.05 & -0.11 & 0.08 & -0.27 & 0.786 \\
\hline HOME & 0.06 & 0.10 & -0.14 & 0.26 & 0.58 & 0.562 & 0.04 & 0.07 & -0.10 & 0.18 & 0.55 & 0.580 \\
\hline Gender $(1=$ male $)$ & -0.09 & 0.06 & -0.21 & 0.03 & -1.54 & 0.124 & -0.08 & 0.05 & -0.19 & 0.02 & -1.62 & 0.105 \\
\hline Maternal Distress & -0.05 & 0.08 & -0.20 & 0.10 & -0.62 & 0.533 & -0.12 & 0.08 & -0.27 & 0.03 & -1.54 & 0.123 \\
\hline Maternal Education & 0.11 & 0.07 & -0.02 & 0.24 & 1.64 & 0.101 & 0.08 & 0.05 & -0.02 & 0.19 & 1.53 & 0.127 \\
\hline Child Cognition & 0.18 & 0.09 & 0.01 & 0.35 & 2.12 & 0.034 & 0.25 & 0.06 & 0.13 & 0.37 & 4.02 & $<.001$ \\
\hline Joint Attention & 0.20 & 0.14 & -0.07 & 0.47 & 1.43 & 0.151 & 0.23 & 0.10 & 0.04 & 0.42 & 2.38 & 0.017 \\
\hline Negative Interaction & 0.02 & 0.09 & -0.16 & 0.19 & 0.19 & 0.848 & -0.01 & 0.10 & -0.20 & 0.18 & -0.07 & 0.945 \\
\hline \multicolumn{13}{|l|}{ Covariances } \\
\hline \multicolumn{13}{|l|}{ Joint Attention } \\
\hline Negative Interaction & -0.42 & 0.12 & -0.65 & -0.19 & -3.57 & $<.001$ & -0.46 & 0.10 & -0.65 & -0.27 & -4.75 & $<.001$ \\
\hline
\end{tabular}




\begin{tabular}{|c|c|c|c|c|c|c|c|c|c|c|c|c|}
\hline & \multicolumn{6}{|c|}{ Black/African American } & \multicolumn{6}{|c|}{ White/European American } \\
\hline & $\begin{array}{c}\text { Std. } \\
\text { Estimate } \\
(\beta)\end{array}$ & $S E$ & $\begin{array}{l}95 \% \text { CI } \\
\text { (Lower) }\end{array}$ & $\begin{array}{l}95 \% \text { CI } \\
\text { (Upper) }\end{array}$ & $z$ & $p$ & $\begin{array}{c}\text { Std. } \\
\text { Estimate } \\
(\beta)\end{array}$ & $S E$ & $\begin{array}{l}95 \% \text { CI } \\
\text { (Lower) }\end{array}$ & $\begin{array}{l}95 \% \text { CI } \\
\text { (Upper) }\end{array}$ & $z$ & $p$ \\
\hline Child Cognition & 0.17 & 0.09 & 0.00 & 0.35 & 1.92 & 0.055 & 0.11 & 0.09 & -0.06 & 0.29 & 1.25 & 0.210 \\
\hline $\begin{array}{l}\text { Parental Mental Health } \\
\text { Maternal Education }\end{array}$ & -0.12 & 0.08 & -0.28 & 0.04 & -1.42 & 0.154 & -0.25 & 0.06 & -0.37 & -0.12 & -3.91 & $<.001$ \\
\hline \multicolumn{13}{|c|}{ Indirect and Total Effect } \\
\hline Indirect & -0.02 & 0.02 & -0.05 & 0.01 & -1.07 & 0.284 & -0.02 & 0.02 & -0.06 & 0.01 & -1.47 & 0.141 \\
\hline Total & -0.11 & 0.06 & -0.22 & 0.01 & -1.81 & 0.071 & -0.11 & 0.05 & -0.21 & 0.00 & -2.03 & 0.043 \\
\hline \multicolumn{13}{|c|}{ Gestational Age $\rightarrow$ Bayley MDI $\rightarrow$ PPVT } \\
\hline Indirect & 0.05 & 0.03 & -0.01 & 0.11 & 1.65 & 0.099 & 0.03 & 0.02 & -0.01 & 0.07 & 1.63 & 0.102 \\
\hline Total & 0.13 & 0.07 & 0.00 & 0.27 & 1.92 & 0.055 & 0.02 & 0.05 & -0.09 & 0.13 & 0.33 & 0.741 \\
\hline \multicolumn{13}{|l|}{ HOME $\rightarrow$ Bayley MDI $\rightarrow$ PPVT } \\
\hline Indirect & 0.02 & 0.02 & -0.01 & 0.06 & 1.24 & 0.216 & 0.04 & 0.02 & 0.00 & 0.07 & 2.07 & 0.038 \\
\hline Total & 0.08 & 0.10 & -0.12 & 0.28 & 0.80 & 0.424 & 0.08 & 0.07 & -0.07 & 0.22 & 1.04 & 0.298 \\
\hline \multicolumn{13}{|c|}{ HOME $\rightarrow$ Joint Attention $\rightarrow$ PPVT } \\
\hline Indirect & 0.08 & 0.06 & -0.04 & 0.20 & 1.29 & 0.198 & 0.10 & 0.05 & 0.00 & 0.20 & 1.94 & 0.052 \\
\hline Total & 0.14 & 0.09 & -0.03 & 0.31 & 1.60 & 0.110 & 0.14 & 0.07 & 0.00 & 0.27 & 2.00 & 0.045 \\
\hline \multicolumn{13}{|c|}{ Maternal Distress $\rightarrow$ HOME $\rightarrow$ PPVT } \\
\hline Indirect & -0.01 & 0.02 & -0.06 & 0.03 & -0.57 & 0.567 & -0.02 & 0.03 & -0.08 & 0.05 & -0.55 & 0.579 \\
\hline Total & -0.06 & 0.07 & -0.21 & 0.08 & -0.84 & 0.402 & -0.14 & 0.07 & -0.27 & 0.00 & -2.02 & 0.044 \\
\hline \multicolumn{13}{|c|}{ Maternal Education $\rightarrow$ Joint Attention $\rightarrow$ PPVT } \\
\hline Indirect & 0.02 & 0.02 & -0.02 & 0.07 & 1.10 & 0.271 & 0.03 & 0.02 & -0.01 & 0.06 & 1.44 & 0.150 \\
\hline Total & 0.13 & 0.07 & 0.00 & 0.27 & 1.95 & 0.051 & 0.11 & 0.05 & 0.00 & 0.22 & 2.02 & 0.043 \\
\hline \multicolumn{13}{|c|}{ Maternal Education $\rightarrow$ HOME $\rightarrow$ PPVT } \\
\hline Indirect & 0.02 & 0.03 & -0.04 & 0.08 & 0.57 & 0.567 & 0.01 & 0.01 & -0.02 & 0.03 & 0.55 & 0.580 \\
\hline Total & 0.13 & 0.07 & -0.01 & 0.26 & 1.80 & 0.072 & 0.09 & 0.05 & -0.02 & 0.20 & 1.66 & 0.096 \\
\hline \multicolumn{13}{|l|}{ Intercepts } \\
\hline Child Attention & 0.65 & 0.09 & 0.48 & 0.82 & 7.61 & $<.001$ & 1.00 & 0.00 & 1.00 & 1.00 & - & - \\
\hline Parental Supportiveness & 0.33 & 0.13 & 0.08 & 0.57 & 2.57 & 0.010 & 3.32 & 0.53 & 2.28 & 4.36 & 6.25 & $<.001$ \\
\hline Child Engagement of Parent & 0.68 & 0.08 & 0.52 & 0.84 & 8.25 & $<.001$ & 0.48 & 0.60 & -0.70 & 1.66 & 0.79 & 0.427 \\
\hline Parental Intrusiveness & 0.14 & 0.16 & -0.17 & 0.45 & 0.88 & 0.379 & 1.21 & 0.42 & 0.39 & 2.03 & 2.90 & 0.004 \\
\hline Parental Negative Regard & 0.86 & 0.06 & 0.75 & 0.98 & 14.29 & $<.001$ & 2.94 & 0.67 & 1.62 & 4.25 & 4.38 & $<.001$ \\
\hline Child Negativity to Parent & 0.56 & 0.11 & 0.34 & 0.78 & 4.91 & $<.001$ & 2.97 & 0.57 & 1.86 & 4.08 & 5.23 & $<.001$ \\
\hline Maternal Distress & 0.29 & 0.12 & 0.05 & 0.53 & 2.41 & 0.016 & 2.99 & 0.60 & 1.82 & 4.16 & 5.01 & $<.001$ \\
\hline Parent-Child Dysfunction & 0.66 & 0.08 & 0.51 & 0.81 & 8.54 & $<.001$ & 2.95 & 0.11 & 2.73 & 3.17 & 26.76 & $<.001$ \\
\hline Parental Dep. Symptoms & 0.55 & 0.09 & 0.37 & 0.74 & 5.83 & $<.001$ & 3.48 & 0.23 & 3.03 & 3.93 & 15.12 & $<.001$ \\
\hline HOME & 0.84 & 0.06 & 0.72 & 0.95 & 14.34 & $<.001$ & 1.38 & 0.05 & 1.28 & 1.48 & 26.05 & $<.001$ \\
\hline Child Cognition (14m) & 1.00 & 0.00 & 1.00 & 1.00 & - & - & 9.35 & 0.65 & 8.07 & 10.63 & 14.31 & $<.001$ \\
\hline Child Vocabulary (36m) & 1.00 & 0.00 & 1.00 & 1.00 & - & - & 6.98 & 0.77 & 5.47 & 8.49 & 9.06 & $<.001$ \\
\hline Maternal Education & 0.90 & 0.05 & 0.80 & 1.00 & 17.56 & $<.001$ & 1.78 & 0.72 & 0.38 & 3.19 & 2.49 & 0.013 \\
\hline Gestational Age & 1.00 & 0.00 & 1.00 & 1.00 & - & - & 2.53 & 0.08 & 2.38 & 2.69 & 31.45 & $<.001$ \\
\hline Gender (1=male) & 0.85 & 0.05 & 0.75 & 0.95 & 16.89 & $<.001$ & 2.42 & 0.26 & 1.92 & 2.92 & 9.46 & $<.001$ \\
\hline Joint Attention & .00 & & .00 & .00 & - & - & .00 & & .00 & .00 & - & - \\
\hline Negative Interaction & .00 & & .00 & .00 & - & - & .00 & & .00 & .00 & - & - \\
\hline Maternal Distress & .00 & & .00 & .00 & - & - & .00 & & .00 & .00 & - & - \\
\hline
\end{tabular}


DIRECT INDIRECT INFLUENCES VOCABULARY DEVELOPMENT

\begin{tabular}{|c|c|c|c|c|c|c|c|c|c|c|c|c|}
\hline & \multicolumn{6}{|c|}{ Black/African American } & \multicolumn{6}{|c|}{ White/European American } \\
\hline & $\begin{array}{c}\text { Std. } \\
\text { Estimate } \\
(\beta)\end{array}$ & $S E$ & $\begin{array}{l}95 \% \text { CI } \\
\text { (Lower) }\end{array}$ & $\begin{array}{l}95 \% \text { CI } \\
\text { (Upper) }\end{array}$ & $z$ & $p$ & $\begin{array}{c}\text { Std. } \\
\text { Estimate } \\
(\beta)\end{array}$ & $S E$ & $\begin{array}{l}95 \% \text { CI } \\
\text { (Lower) }\end{array}$ & $\begin{array}{l}95 \% \text { CI } \\
\text { (Upper) }\end{array}$ & $z$ & $p$ \\
\hline \multicolumn{13}{|l|}{ Variances } \\
\hline Child Attention & 0.65 & 0.09 & 0.48 & 0.82 & 7.61 & $<.001$ & 0.72 & 0.09 & 0.55 & 0.90 & 8.24 & $<.001$ \\
\hline Parental Supportiveness & 0.33 & 0.13 & 0.08 & 0.57 & 2.57 & 0.010 & 0.20 & 0.13 & -0.05 & 0.44 & 1.58 & 0.114 \\
\hline Child Engagement of Parent & 0.68 & 0.08 & 0.52 & 0.84 & 8.25 & $<.001$ & 0.67 & 0.07 & 0.53 & 0.80 & 9.87 & $<.001$ \\
\hline Parental Intrusiveness & 0.14 & 0.16 & -0.17 & 0.45 & 0.88 & 0.379 & 0.39 & 0.13 & 0.14 & 0.64 & 3.09 & 0.002 \\
\hline Parental Negative Regard & 0.86 & 0.06 & 0.75 & 0.98 & 14.29 & $<.001$ & 0.71 & 0.09 & 0.54 & 0.88 & 8.27 & $<.001$ \\
\hline Child Negativity to Parent & 0.56 & 0.11 & 0.34 & 0.78 & 4.91 & $<.001$ & 0.42 & 0.12 & 0.18 & 0.66 & 3.49 & $<.001$ \\
\hline Maternal Distress & 0.29 & 0.12 & 0.05 & 0.53 & 2.41 & 0.016 & 0.41 & 0.09 & 0.24 & 0.58 & 4.72 & $<.001$ \\
\hline Parent-Child Dysfunction & 0.66 & 0.08 & 0.51 & 0.81 & 8.54 & $<.001$ & 0.64 & 0.09 & 0.47 & 0.81 & 7.46 & $<.001$ \\
\hline Parental Dep. Symptoms & 0.55 & 0.09 & 0.37 & 0.74 & 5.83 & $<.001$ & 0.61 & 0.07 & 0.46 & 0.75 & 8.31 & $<.001$ \\
\hline Child Vocabulary $(36 \mathrm{~m})$ & 0.84 & 0.06 & 0.72 & 0.95 & 14.34 & $<.001$ & 0.78 & 0.05 & 0.67 & 0.89 & 14.43 & $<.001$ \\
\hline Gender $(1=$ male $)$ & 1.00 & 0.00 & 1.00 & 1.00 & - & - & 1.00 & 0.00 & 1.00 & 1.00 & - & - \\
\hline Maternal Education & 1.00 & 0.00 & 1.00 & 1.00 & - & - & 1.00 & 0.00 & 1.00 & 1.00 & - & _ \\
\hline Child Cognition & 0.90 & 0.05 & 0.80 & 1.00 & 17.56 & $<.001$ & 0.95 & 0.03 & 0.90 & 1.01 & 34.67 & $<.001$ \\
\hline Gestational Age & 1.00 & 0.00 & 1.00 & 1.00 & - & - & 1.00 & 0.00 & 1.00 & 1.00 & - & 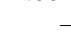 \\
\hline HOME & 0.85 & 0.05 & 0.75 & 0.95 & 16.89 & $<.001$ & 0.72 & 0.07 & 0.57 & 0.86 & 9.85 & $<.001$ \\
\hline Joint Attention & 0.79 & 0.11 & 0.58 & 1.00 & 7.42 & $<.001$ & 0.78 & 0.10 & 0.57 & 0.98 & 7.48 & $<.001$ \\
\hline Negative Interaction & 0.97 & 0.04 & 0.90 & 1.04 & 27.76 & $<.001$ & 0.95 & 0.04 & 0.88 & 1.03 & 23.79 & $<.001$ \\
\hline Maternal Distress & 1.00 & 0.00 & 1.00 & 1.00 & 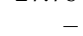 & - & 1.00 & 0.00 & 1.00 & 1.00 & - & - \\
\hline
\end{tabular}

Note: $* * * p<.001, * * p<.01, * p<.05$ 
Table S7

Standardized estimates for SEM predicting variation in children's receptive vocabulary knowledge (PPVT) at Pre-K (approximately $48 \mathrm{~m}$ ) based on predictors measured at $14 \mathrm{~m}$.

\begin{tabular}{|c|c|c|c|c|c|c|c|c|c|c|c|c|}
\hline & \multicolumn{6}{|c|}{ Black/African American } & \multicolumn{6}{|c|}{ White/European American } \\
\hline & $\begin{array}{c}\text { Std. } \\
\text { Estimate } \\
(\beta)\end{array}$ & $S E$ & $\begin{array}{l}95 \% \text { CI } \\
\text { (Lower) }\end{array}$ & $\begin{array}{l}95 \% \text { CI } \\
\text { (Upper) }\end{array}$ & $z$ & $p$ & $\begin{array}{c}\text { Std. } \\
\text { Estimate } \\
(\beta)\end{array}$ & $S E$ & $\begin{array}{l}95 \% \text { CI } \\
\text { (Lower) }\end{array}$ & $\begin{array}{l}95 \% \text { CI } \\
\text { (Upper) }\end{array}$ & $z$ & $p$ \\
\hline \multicolumn{13}{|l|}{ Latent Variables } \\
\hline \multicolumn{13}{|l|}{ Joint Attention $=\sim$} \\
\hline Child Attention & 0.63 & 0.07 & 0.49 & 0.78 & 8.48 & $<.001$ & 0.63 & 0.08 & 0.48 & 0.77 & 8.33 & $<.001$ \\
\hline Parental Supportiveness & 0.79 & 0.07 & 0.65 & 0.94 & 10.69 & $<.001$ & 0.88 & 0.06 & 0.76 & 1.00 & 13.97 & $<.001$ \\
\hline Child Engagement of Parent & 0.57 & 0.08 & 0.41 & 0.73 & 6.96 & $<.001$ & 0.62 & 0.05 & 0.52 & 0.72 & 12.23 & $<.001$ \\
\hline \multicolumn{13}{|l|}{ Negative Interaction $=\sim$} \\
\hline Parental Intrusiveness & 0.90 & 0.09 & 0.73 & 1.07 & 10.25 & $<.001$ & 0.76 & 0.09 & 0.58 & 0.94 & 8.06 & $<.001$ \\
\hline Parental Negative Regard & 0.43 & 0.09 & 0.25 & 0.61 & 4.64 & $<.001$ & 0.55 & 0.08 & 0.39 & 0.71 & 6.65 & $<.001$ \\
\hline Child Negativity to Parent & 0.64 & 0.09 & 0.46 & 0.83 & 6.78 & $<.001$ & 0.79 & 0.09 & 0.62 & 0.96 & 9.06 & $<.001$ \\
\hline \multicolumn{13}{|l|}{ Maternal Distress = } \\
\hline Maternal Distress & 0.84 & 0.09 & 0.67 & 1.00 & 9.64 & $<.001$ & 0.75 & 0.07 & 0.62 & 0.88 & 11.25 & $<.001$ \\
\hline Parent-Child Dysfunction & 0.59 & 0.07 & 0.45 & 0.72 & 8.52 & $<.001$ & 0.51 & 0.07 & 0.37 & 0.64 & 7.55 & $<.001$ \\
\hline Parental Dep. Symptoms & 0.64 & 0.08 & 0.48 & 0.80 & 7.89 & $<.001$ & 0.63 & 0.07 & 0.50 & 0.77 & 9.17 & $<.001$ \\
\hline \multicolumn{13}{|l|}{ Regressions } \\
\hline \multicolumn{13}{|l|}{ HOME } \\
\hline Maternal Distress & -0.24 & 0.10 & -0.43 & -0.05 & -2.49 & 0.013 & -0.33 & 0.08 & -0.49 & -0.17 & -4.09 & $<.001$ \\
\hline Maternal Education & 0.30 & 0.06 & 0.17 & 0.42 & 4.71 & $<.001$ & 0.25 & 0.06 & 0.12 & 0.38 & 3.85 & $<.001$ \\
\hline \multicolumn{13}{|l|}{ Negative Interaction } \\
\hline Maternal Education & 0.05 & 0.11 & -0.16 & 0.26 & 0.46 & 0.645 & -0.17 & 0.07 & -0.31 & -0.02 & -2.23 & 0.025 \\
\hline HOME & -0.23 & 0.12 & -0.47 & 0.01 & -1.89 & 0.058 & -0.07 & 0.11 & -0.28 & 0.14 & -0.64 & 0.522 \\
\hline \multicolumn{13}{|l|}{ Joint Attention } \\
\hline Maternal Education & 0.02 & 0.10 & -0.17 & 0.22 & 0.21 & 0.833 & 0.13 & 0.07 & -0.01 & 0.27 & 1.77 & 0.078 \\
\hline HOME & 0.48 & 0.13 & 0.23 & 0.73 & 3.77 & $<.001$ & 0.37 & 0.09 & 0.19 & 0.55 & 3.99 & $<.001$ \\
\hline \multicolumn{13}{|l|}{ Child Cognition } \\
\hline Gestational Age & 0.28 & 0.09 & 0.09 & 0.46 & 2.90 & 0.004 & 0.14 & 0.08 & -0.01 & 0.29 & 1.77 & 0.077 \\
\hline Gender (1=male) & -0.09 & 0.08 & -0.25 & 0.07 & -1.16 & 0.246 & -0.12 & 0.07 & -0.25 & 0.01 & -1.74 & 0.082 \\
\hline HOME & 0.07 & 0.10 & -0.12 & 0.26 & 0.77 & 0.442 & 0.15 & 0.06 & 0.02 & 0.27 & 2.31 & 0.021 \\
\hline \multicolumn{13}{|l|}{ Child Vocabulary $(36 \mathrm{~m}) \sim$} \\
\hline Gestational Age & 0.03 & 0.08 & -0.13 & 0.18 & 0.35 & 0.728 & 0.05 & 0.06 & -0.06 & 0.16 & 0.88 & 0.380 \\
\hline HOME & -0.03 & 0.11 & -0.25 & 0.19 & -0.29 & 0.768 & 0.17 & 0.07 & 0.03 & 0.31 & 2.43 & 0.015 \\
\hline Gender ( $1=$ male $)$ & -0.02 & 0.07 & -0.15 & 0.12 & -0.29 & 0.774 & -0.01 & 0.05 & -0.12 & 0.09 & -0.25 & 0.799 \\
\hline Maternal Distress & -0.01 & 0.10 & -0.21 & 0.18 & -0.12 & 0.904 & -0.30 & 0.08 & -0.45 & -0.15 & -3.84 & $<.001$ \\
\hline Maternal Education & 0.25 & 0.08 & 0.10 & 0.40 & 3.27 & 0.001 & 0.00 & 0.06 & -0.11 & 0.11 & -0.07 & 0.943 \\
\hline Child Cognition & 0.08 & 0.09 & -0.11 & 0.26 & 0.83 & 0.408 & 0.29 & 0.07 & 0.15 & 0.42 & 4.25 & $<.001$ \\
\hline Joint Attention & 0.26 & 0.16 & -0.05 & 0.58 & 1.64 & 0.100 & 0.13 & 0.10 & -0.06 & 0.32 & 1.34 & 0.180 \\
\hline Negative Interaction & 0.09 & 0.11 & -0.13 & 0.31 & 0.79 & 0.428 & 0.03 & 0.09 & -0.14 & 0.20 & 0.34 & 0.731 \\
\hline \multicolumn{13}{|l|}{ Covariances } \\
\hline \multicolumn{13}{|l|}{ Joint Attention } \\
\hline Negative Interaction & -0.50 & 0.13 & -0.74 & -0.25 & -3.94 & $<.001$ & -0.52 & 0.09 & -0.69 & -0.35 & -6.05 & $<.001$ \\
\hline
\end{tabular}




\begin{tabular}{|c|c|c|c|c|c|c|c|c|c|c|c|c|}
\hline & \multicolumn{6}{|c|}{ Black/African American } & \multicolumn{6}{|c|}{ White/European American } \\
\hline & $\begin{array}{c}\text { Std. } \\
\text { Estimate } \\
(\beta)\end{array}$ & $S E$ & $\begin{array}{l}95 \% \text { CI } \\
\text { (Lower) }\end{array}$ & $\begin{array}{l}95 \% \text { CI } \\
\text { (Upper) }\end{array}$ & $z$ & $p$ & $\begin{array}{c}\text { Std. } \\
\text { Estimate } \\
(\beta)\end{array}$ & $S E$ & $\begin{array}{l}95 \% \text { CI } \\
\text { (Lower) }\end{array}$ & $\begin{array}{l}95 \% \text { CI } \\
\text { (Upper) }\end{array}$ & $z$ & $p$ \\
\hline Child Cognition & 0.21 & 0.10 & 0.02 & 0.40 & 2.13 & 0.033 & 0.10 & 0.09 & -0.07 & 0.28 & 1.19 & 0.236 \\
\hline $\begin{array}{l}\text { Parental Mental Health } \\
\text { Maternal Education }\end{array}$ & -0.15 & 0.09 & -0.33 & 0.03 & -1.67 & 0.094 & -0.22 & 0.08 & -0.38 & -0.06 & -2.72 & 0.006 \\
\hline \multicolumn{13}{|c|}{ Indirect and Total Effect } \\
\hline Indirect & -0.01 & 0.01 & -0.03 & 0.01 & -0.75 & 0.454 & -0.03 & 0.02 & -0.07 & 0.01 & -1.69 & 0.092 \\
\hline Total & -0.03 & 0.07 & -0.16 & 0.11 & -0.39 & 0.694 & -0.05 & 0.06 & -0.16 & 0.06 & -0.84 & 0.398 \\
\hline \multicolumn{13}{|c|}{ Gestational Age $\rightarrow$ Bayley MDI $\rightarrow$ PPVT } \\
\hline Indirect & 0.02 & 0.03 & -0.03 & 0.08 & 0.75 & 0.452 & 0.04 & 0.02 & -0.01 & 0.08 & 1.67 & 0.094 \\
\hline Total & 0.05 & 0.07 & -0.10 & 0.19 & 0.66 & 0.508 & 0.09 & 0.05 & -0.02 & 0.19 & 1.62 & 0.106 \\
\hline \multicolumn{13}{|l|}{ HOME $\rightarrow$ Bayley MDI $\rightarrow$ PPVT } \\
\hline Indirect & 0.01 & 0.01 & -0.02 & 0.03 & 0.52 & 0.602 & 0.04 & 0.02 & 0.00 & 0.08 & 2.15 & 0.031 \\
\hline Total & -0.03 & 0.11 & -0.25 & 0.20 & -0.24 & 0.813 & 0.21 & 0.07 & 0.08 & 0.35 & 3.04 & 0.002 \\
\hline \multicolumn{13}{|c|}{ HOME $\rightarrow$ Joint Attention $\rightarrow$ PPVT } \\
\hline Indirect & 0.13 & 0.09 & -0.05 & 0.30 & 1.44 & 0.149 & 0.05 & 0.04 & -0.02 & 0.12 & 1.30 & 0.194 \\
\hline Total & 0.09 & 0.10 & -0.10 & 0.29 & 0.95 & 0.341 & 0.22 & 0.07 & 0.08 & 0.35 & 3.21 & 0.001 \\
\hline \multicolumn{13}{|c|}{ Maternal Distress $\rightarrow$ HOME $\rightarrow$ PPVT } \\
\hline Indirect & 0.01 & 0.03 & -0.05 & 0.06 & 0.29 & 0.770 & -0.06 & 0.03 & -0.11 & -0.01 & -2.25 & 0.024 \\
\hline Total & 0.00 & 0.10 & -0.19 & 0.18 & -0.04 & 0.965 & -0.35 & 0.07 & -0.49 & -0.21 & -4.99 & $<.001$ \\
\hline \multicolumn{13}{|c|}{ Maternal Education $\rightarrow$ Joint Attention $\rightarrow$ PPVT } \\
\hline Indirect & 0.01 & 0.03 & -0.05 & 0.06 & 0.21 & 0.830 & 0.02 & 0.02 & -0.02 & 0.05 & 1.01 & 0.311 \\
\hline Total & 0.26 & 0.08 & 0.10 & 0.41 & 3.32 & 0.001 & 0.01 & 0.06 & -0.10 & 0.12 & 0.21 & 0.831 \\
\hline \multicolumn{13}{|c|}{ Maternal Education $\rightarrow$ HOME $\rightarrow$ PPVT } \\
\hline Indirect & -0.01 & 0.03 & -0.07 & 0.05 & -0.29 & 0.769 & 0.04 & 0.02 & 0.00 & 0.08 & 2.03 & 0.043 \\
\hline Total & 0.24 & 0.07 & 0.09 & 0.39 & 3.22 & 0.001 & 0.04 & 0.06 & -0.08 & 0.15 & 0.66 & 0.507 \\
\hline \multicolumn{13}{|l|}{ Intercepts } \\
\hline Child Attention & 2.50 & 0.55 & 1.42 & 3.58 & 4.54 & $<.001$ & 2.93 & 0.56 & 1.84 & 4.02 & 5.27 & $<.001$ \\
\hline Parental Supportiveness & 0.85 & 0.62 & -0.36 & 2.06 & 1.37 & 0.169 & 0.63 & 0.78 & -0.90 & 2.16 & 0.81 & 0.420 \\
\hline Child Engagement of Parent & 1.17 & 0.47 & 0.26 & 2.09 & 2.51 & 0.012 & 1.11 & 0.52 & 0.09 & 2.14 & 2.14 & 0.032 \\
\hline Parental Intrusiveness & 3.59 & 0.61 & 2.40 & 4.79 & 5.91 & $<.001$ & 2.76 & 0.90 & 0.99 & 4.53 & 3.05 & 0.002 \\
\hline Parental Negative Regard & 2.45 & 0.36 & 1.75 & 3.14 & 6.88 & $<.001$ & 2.85 & 0.77 & 1.34 & 4.35 & 3.71 & $<.001$ \\
\hline Child Negativity to Parent & 2.96 & 0.54 & 1.90 & 4.02 & 5.47 & $<.001$ & 2.83 & 0.87 & 1.12 & 4.55 & 3.24 & 0.001 \\
\hline Maternal Distress & 2.89 & 0.14 & 2.61 & 3.16 & 20.71 & $<.001$ & 2.99 & 0.12 & 2.75 & 3.22 & 24.91 & $<.001$ \\
\hline Parent-Child Dysfunction & 2.67 & 0.25 & 2.17 & 3.16 & 10.55 & $<.001$ & 3.71 & 0.25 & 3.22 & 4.20 & 14.73 & $<.001$ \\
\hline Parental Dep. Symptoms & 1.42 & 0.09 & 1.24 & 1.59 & 15.97 & $<.001$ & 1.42 & 0.06 & 1.30 & 1.54 & 23.22 & $<.001$ \\
\hline HOME & 6.79 & 0.60 & 5.61 & 7.97 & 11.31 & $<.001$ & 10.31 & 0.71 & 8.93 & 11.69 & 14.61 & $<.001$ \\
\hline Child Cognition (14m) & 8.99 & 1.24 & 6.56 & 11.41 & 7.27 & $<.001$ & 6.64 & 0.88 & 4.92 & 8.37 & 7.54 & $<.001$ \\
\hline Child Vocabulary (36m) & 4.11 & 1.08 & 1.99 & 6.24 & 3.80 & $<.001$ & 2.82 & 0.82 & 1.23 & 4.42 & 3.46 & 0.001 \\
\hline Maternal Education & 2.23 & 0.07 & 2.09 & 2.37 & 31.07 & $<.001$ & 2.52 & 0.09 & 2.34 & 2.69 & 28.70 & $<.001$ \\
\hline Gestational Age & 2.42 & 0.30 & 1.84 & 3.00 & 8.14 & $<.001$ & 2.35 & 0.25 & 1.87 & 2.83 & 9.61 & $<.001$ \\
\hline Gender (1=male) & 1.11 & 0.09 & 0.93 & 1.29 & 11.88 & $<.001$ & 1.00 & 0.07 & 0.86 & 1.13 & 14.31 & $<.001$ \\
\hline Joint Attention & .00 & & .00 & .00 & - & - & .00 & & .00 & .00 & - & - \\
\hline Negative Interaction & .00 & & .00 & .00 & - & - & .00 & & .00 & .00 & - & - \\
\hline Maternal Distress & .00 & & .00 & .00 & - & - & .00 & & .00 & .00 & - & - \\
\hline
\end{tabular}


DIRECT INDIRECT INFLUENCES VOCABULARY DEVELOPMENT

\begin{tabular}{|c|c|c|c|c|c|c|c|c|c|c|c|c|}
\hline & \multicolumn{6}{|c|}{ Black/African American } & \multicolumn{6}{|c|}{ White/European American } \\
\hline & $\begin{array}{c}\text { Std. } \\
\text { Estimate } \\
(\beta)\end{array}$ & $S E$ & $\begin{array}{l}95 \% \text { CI } \\
\text { (Lower) }\end{array}$ & $\begin{array}{l}95 \% \text { CI } \\
\text { (Upper) }\end{array}$ & $z$ & $p$ & $\begin{array}{c}\text { Std. } \\
\text { Estimate } \\
(\beta)\end{array}$ & $S E$ & $\begin{array}{l}95 \% \text { CI } \\
\text { (Lower) }\end{array}$ & $\begin{array}{l}95 \% \text { CI } \\
\text { (Upper) }\end{array}$ & $z$ & $p$ \\
\hline \multicolumn{13}{|l|}{ Variances } \\
\hline Child Attention & 0.60 & 0.09 & 0.41 & 0.78 & 6.31 & $<.001$ & 0.61 & 0.09 & 0.42 & 0.79 & 6.46 & $<.001$ \\
\hline Parental Supportiveness & 0.37 & 0.12 & 0.14 & 0.60 & 3.15 & 0.002 & 0.23 & 0.11 & 0.01 & 0.44 & 2.04 & 0.042 \\
\hline Child Engagement of Parent & 0.67 & 0.09 & 0.49 & 0.86 & 7.12 & $<.001$ & 0.61 & 0.06 & 0.49 & 0.74 & 9.61 & $<.001$ \\
\hline Parental Intrusiveness & 0.19 & 0.16 & -0.12 & 0.50 & 1.20 & 0.231 & 0.42 & 0.14 & 0.14 & 0.70 & 2.95 & 0.003 \\
\hline Parental Negative Regard & 0.82 & 0.08 & 0.66 & 0.97 & 10.31 & $<.001$ & 0.70 & 0.09 & 0.52 & 0.88 & 7.62 & $<.001$ \\
\hline Child Negativity to Parent & 0.59 & 0.12 & 0.35 & 0.83 & 4.87 & $<.001$ & 0.38 & 0.14 & 0.11 & 0.65 & 2.73 & 0.006 \\
\hline Maternal Distress & 0.30 & 0.14 & 0.02 & 0.59 & 2.09 & 0.037 & 0.44 & 0.10 & 0.25 & 0.64 & 4.45 & $<.001$ \\
\hline Parent-Child Dysfunction & 0.65 & 0.08 & 0.49 & 0.81 & 8.06 & $<.001$ & 0.74 & 0.07 & 0.61 & 0.88 & 10.98 & $<.001$ \\
\hline Parental Dep. Symptoms & 0.59 & 0.10 & 0.39 & 0.79 & 5.67 & $<.001$ & 0.60 & 0.09 & 0.43 & 0.77 & 6.95 & $<.001$ \\
\hline Child Vocabulary $(36 \mathrm{~m})$ & 0.85 & 0.06 & 0.73 & 0.98 & 13.68 & $<.001$ & 0.68 & 0.05 & 0.57 & 0.78 & 12.83 & $<.001$ \\
\hline Gender $(1=$ male $)$ & 1.00 & 0.00 & 1.00 & 1.00 & - & - & 1.00 & 0.00 & 1.00 & 1.00 & - & - \\
\hline Maternal Education & 1.00 & 0.00 & 1.00 & 1.00 & - & - & 1.00 & 0.00 & 1.00 & 1.00 & - & _ \\
\hline Child Cognition & 0.91 & 0.06 & 0.80 & 1.02 & 16.13 & $<.001$ & 0.95 & 0.03 & 0.88 & 1.01 & 27.52 & $<.001$ \\
\hline Gestational Age & 1.00 & 0.00 & 1.00 & 1.00 & - & - & 1.00 & 0.00 & 1.00 & 1.00 & - & 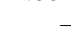 \\
\hline HOME & 0.83 & 0.06 & 0.71 & 0.95 & 13.73 & $<.001$ & 0.79 & 0.06 & 0.68 & 0.91 & 13.47 & $<.001$ \\
\hline Joint Attention & 0.76 & 0.12 & 0.52 & 1.00 & 6.27 & $<.001$ & 0.82 & 0.07 & 0.68 & 0.96 & 11.15 & $<.001$ \\
\hline Negative Interaction & 0.95 & 0.05 & 0.85 & 1.05 & 18.85 & $<.001$ & 0.96 & 0.04 & 0.88 & 1.04 & 24.41 & $<.001$ \\
\hline Maternal Distress & 1.00 & 0.00 & 1.00 & 1.00 & - & - & 1.00 & 0.00 & 1.00 & 1.00 & 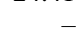 & - \\
\hline
\end{tabular}

Note: $* * * p<.001, * * p<.01, * p<.05$ 
Table S8

Standardized estimates for SEM predicting variation in children's receptive vocabulary knowledge (PPVT) at Grade 5 (approximately $120 \mathrm{~m}$ ) based on predictors measured at $14 \mathrm{~m}$.

\begin{tabular}{|c|c|c|c|c|c|c|c|c|c|c|c|c|}
\hline & \multicolumn{6}{|c|}{ Black/African American } & \multicolumn{6}{|c|}{ White/European American } \\
\hline & $\begin{array}{c}\text { Std. } \\
\text { Estimate } \\
(\beta)\end{array}$ & $S E$ & $\begin{array}{l}95 \% \text { CI } \\
\text { (Lower) }\end{array}$ & $\begin{array}{l}95 \% \text { CI } \\
\text { (Upper) }\end{array}$ & $z$ & $p$ & $\begin{array}{c}\text { Std. } \\
\text { Estimate } \\
(\beta)\end{array}$ & $S E$ & $\begin{array}{l}95 \% \text { CI } \\
\text { (Lower) }\end{array}$ & $\begin{array}{l}95 \% \text { CI } \\
\text { (Upper) }\end{array}$ & $z$ & $p$ \\
\hline \multicolumn{13}{|l|}{ Latent Variables } \\
\hline \multicolumn{13}{|l|}{ Joint Attention = } \\
\hline Child Attention & 0.67 & 0.09 & 0.49 & 0.85 & 7.15 & $<.001$ & 0.64 & 0.09 & 0.47 & 0.80 & 7.37 & $<.001$ \\
\hline Parental Supportiveness & 0.80 & 0.08 & 0.64 & 0.96 & 9.86 & $<.001$ & 0.87 & 0.07 & 0.74 & 1.00 & 13.00 & $<.001$ \\
\hline Child Engagement of Parent & 0.62 & 0.08 & 0.45 & 0.79 & 7.29 & $<.001$ & 0.64 & 0.06 & 0.54 & 0.75 & 11.67 & $<.001$ \\
\hline \multicolumn{13}{|l|}{ Negative Interaction $=\sim$} \\
\hline Parental Intrusiveness & 0.91 & 0.13 & 0.67 & 1.16 & 7.28 & $<.001$ & 0.68 & 0.11 & 0.46 & 0.90 & 6.14 & $<.001$ \\
\hline Parental Negative Regard & 0.42 & 0.12 & 0.19 & 0.65 & 3.56 & $<.001$ & 0.61 & 0.10 & 0.42 & 0.79 & 6.38 & $<.001$ \\
\hline Child Negativity to Parent & 0.63 & 0.11 & 0.41 & 0.85 & 5.56 & $<.001$ & 0.84 & 0.09 & 0.66 & 1.02 & 9.16 & $<.001$ \\
\hline \multicolumn{13}{|l|}{ Maternal Distress = } \\
\hline Maternal Distress & 0.91 & 0.14 & 0.64 & 1.18 & 6.61 & $<.001$ & 0.69 & 0.08 & 0.54 & 0.84 & 9.04 & $<.001$ \\
\hline Parent-Child Dysfunction & 0.53 & 0.09 & 0.36 & 0.71 & 5.96 & $<.001$ & 0.55 & 0.09 & 0.37 & 0.74 & 5.89 & $<.001$ \\
\hline Parental Dep. Symptoms & 0.60 & 0.11 & 0.39 & 0.81 & 5.64 & $<.001$ & 0.59 & 0.10 & 0.40 & 0.78 & 6.17 & $<.001$ \\
\hline \multicolumn{13}{|l|}{ Regressions } \\
\hline \multicolumn{13}{|l|}{ HOME } \\
\hline Maternal Distress & -0.14 & 0.15 & -0.44 & 0.16 & -0.91 & 0.362 & -0.40 & 0.10 & -0.59 & -0.20 & -3.95 & $<.001$ \\
\hline Maternal Education & 0.32 & 0.08 & 0.18 & 0.47 & 4.32 & $<.001$ & 0.19 & 0.08 & 0.04 & 0.33 & 2.43 & 0.015 \\
\hline \multicolumn{13}{|l|}{ Negative Interaction } \\
\hline Maternal Education & -0.01 & 0.11 & -0.23 & 0.21 & -0.11 & 0.916 & -0.11 & 0.08 & -0.28 & 0.05 & -1.32 & 0.186 \\
\hline HOME & -0.27 & 0.18 & -0.62 & 0.08 & -1.54 & 0.125 & -0.07 & 0.13 & -0.32 & 0.18 & -0.54 & 0.592 \\
\hline \multicolumn{13}{|l|}{ Joint Attention } \\
\hline Maternal Education & -0.08 & 0.12 & -0.30 & 0.15 & -0.65 & 0.518 & 0.12 & 0.08 & -0.04 & 0.28 & 1.41 & 0.159 \\
\hline HOME & 0.59 & 0.17 & 0.26 & 0.92 & 3.47 & 0.001 & 0.33 & 0.11 & 0.11 & 0.54 & 3.01 & 0.003 \\
\hline \multicolumn{13}{|l|}{ Child Cognition } \\
\hline Gestational Age & 0.39 & 0.12 & 0.16 & 0.63 & 3.28 & 0.001 & 0.09 & 0.08 & -0.07 & 0.25 & 1.07 & 0.283 \\
\hline Gender (1=male) & -0.08 & 0.10 & -0.27 & 0.11 & -0.84 & 0.402 & -0.07 & 0.08 & -0.22 & 0.09 & -0.83 & 0.408 \\
\hline HOME & 0.00 & 0.12 & -0.23 & 0.23 & 0.00 & 0.998 & 0.16 & 0.07 & 0.02 & 0.30 & 2.28 & 0.023 \\
\hline \multicolumn{13}{|l|}{ Child Vocabulary $(36 \mathrm{~m}) \sim$} \\
\hline Gestational Age & 0.01 & 0.09 & -0.17 & 0.18 & 0.05 & 0.956 & 0.08 & 0.08 & -0.07 & 0.23 & 1.08 & 0.279 \\
\hline HOME & 0.01 & 0.12 & -0.23 & 0.25 & 0.09 & 0.930 & 0.17 & 0.08 & 0.00 & 0.33 & 1.96 & 0.050 \\
\hline Gender $(1=$ male $)$ & -0.06 & 0.08 & -0.22 & 0.10 & -0.77 & 0.441 & 0.09 & 0.07 & -0.04 & 0.22 & 1.34 & 0.180 \\
\hline Maternal Distress & -0.07 & 0.10 & -0.27 & 0.12 & -0.72 & 0.472 & -0.16 & 0.10 & -0.36 & 0.04 & -1.57 & 0.116 \\
\hline Maternal Education & 0.18 & 0.09 & 0.00 & 0.36 & 2.00 & 0.046 & 0.06 & 0.06 & -0.06 & 0.18 & 0.97 & 0.332 \\
\hline Child Cognition & 0.15 & 0.11 & -0.07 & 0.37 & 1.32 & 0.185 & 0.29 & 0.08 & 0.14 & 0.43 & 3.81 & $<.001$ \\
\hline Joint Attention & 0.32 & 0.17 & -0.02 & 0.66 & 1.85 & 0.064 & 0.23 & 0.11 & 0.02 & 0.44 & 2.11 & 0.035 \\
\hline Negative Interaction & 0.05 & 0.14 & -0.22 & 0.32 & 0.34 & 0.736 & 0.11 & 0.12 & -0.13 & 0.34 & 0.90 & 0.370 \\
\hline \multirow{2}{*}{\multicolumn{13}{|c|}{$\begin{array}{l}\text { Covariances } \\
\text { Joint Attention }\end{array}$}} \\
\hline & & & & & & & & & & & & \\
\hline Negative Interaction & -0.45 & 0.15 & -0.75 & -0.16 & -3.02 & 0.003 & -0.56 & 0.09 & -0.74 & -0.39 & -6.28 & $<.001$ \\
\hline
\end{tabular}




\begin{tabular}{|c|c|c|c|c|c|c|c|c|c|c|c|c|}
\hline & \multicolumn{6}{|c|}{ Black/African American } & \multicolumn{6}{|c|}{ White/European American } \\
\hline & $\begin{array}{c}\text { Std. } \\
\text { Estimate } \\
(\beta)\end{array}$ & $S E$ & $\begin{array}{l}95 \% \text { CI } \\
\text { (Lower) }\end{array}$ & $\begin{array}{l}95 \% \text { CI } \\
\text { (Upper) }\end{array}$ & $z$ & $p$ & $\begin{array}{c}\text { Std. } \\
\text { Estimate } \\
(\beta)\end{array}$ & $S E$ & $\begin{array}{l}95 \% \text { CI } \\
\text { (Lower) }\end{array}$ & $\begin{array}{l}95 \% \text { CI } \\
\text { (Upper) }\end{array}$ & $z$ & $p$ \\
\hline Child Cognition & 0.29 & 0.12 & 0.06 & 0.52 & 2.44 & 0.015 & 0.06 & 0.10 & -0.13 & 0.25 & 0.60 & 0.549 \\
\hline $\begin{array}{l}\text { Parental Mental Health } \\
\text { Maternal Education }\end{array}$ & -0.13 & 0.10 & -0.33 & 0.07 & -1.28 & 0.201 & -0.26 & 0.09 & -0.44 & -0.09 & -2.97 & 0.003 \\
\hline \multicolumn{13}{|c|}{ Indirect and Total Effect } \\
\hline Indirect & 0.16 & 0.09 & -0.01 & 0.33 & 1.79 & 0.073 & 0.09 & 0.06 & -0.04 & 0.21 & 1.38 & 0.168 \\
\hline Total & 0.19 & 0.09 & 0.01 & 0.36 & 2.08 & 0.037 & 0.09 & 0.07 & -0.04 & 0.22 & 1.34 & 0.180 \\
\hline \multicolumn{13}{|c|}{ Gestational Age $\rightarrow$ Bayley MDI $\rightarrow$ PPVT } \\
\hline Indirect & 0.06 & 0.09 & -0.10 & 0.23 & 0.75 & 0.456 & 0.11 & 0.07 & -0.03 & 0.25 & 1.50 & 0.135 \\
\hline Total & -0.07 & 0.08 & -0.23 & 0.09 & -0.91 & 0.365 & 0.07 & 0.07 & -0.07 & 0.20 & 1.00 & 0.317 \\
\hline \multicolumn{13}{|c|}{ HOME $\rightarrow$ Bayley MDI $\rightarrow$ PPVT } \\
\hline Indirect & -0.01 & 0.02 & -0.05 & 0.02 & -0.70 & 0.486 & -0.02 & 0.02 & -0.07 & 0.03 & -0.81 & 0.417 \\
\hline Total & 0.01 & 0.12 & -0.22 & 0.24 & 0.09 & 0.928 & 0.21 & 0.09 & 0.04 & 0.38 & 2.48 & 0.013 \\
\hline \multicolumn{13}{|c|}{ HOME $\rightarrow$ Joint Attention $\rightarrow$ PPVT } \\
\hline Indirect & 0.20 & 0.12 & -0.04 & 0.43 & 1.65 & 0.100 & 0.24 & 0.08 & 0.08 & 0.40 & 2.97 & 0.003 \\
\hline Total & -0.07 & 0.10 & -0.27 & 0.12 & -0.74 & 0.459 & -0.23 & 0.09 & -0.40 & -0.05 & -2.58 & 0.010 \\
\hline \multicolumn{13}{|c|}{ Maternal Distress $\rightarrow$ HOME $\rightarrow$ PPVT } \\
\hline Indirect & 0.06 & 0.05 & -0.04 & 0.16 & 1.17 & 0.243 & 0.03 & 0.02 & -0.02 & 0.07 & 1.09 & 0.275 \\
\hline Total & 0.00 & 0.04 & -0.07 & 0.08 & 0.09 & 0.930 & 0.03 & 0.02 & -0.01 & 0.07 & 1.51 & 0.132 \\
\hline \multicolumn{13}{|c|}{ Maternal Education $\rightarrow$ Joint Attention $\rightarrow$ PPVT } \\
\hline Indirect & 0.00 & 0.02 & -0.03 & 0.03 & 0.00 & 0.998 & 0.05 & 0.02 & 0.00 & 0.09 & 1.98 & 0.048 \\
\hline Total & 0.19 & 0.12 & -0.05 & 0.43 & 1.55 & 0.122 & 0.07 & 0.04 & -0.01 & 0.16 & 1.76 & 0.078 \\
\hline \multicolumn{13}{|c|}{ Maternal Education $\rightarrow$ HOME $\rightarrow$ PPVT } \\
\hline Indirect & -0.02 & 0.04 & -0.10 & 0.05 & -0.65 & 0.516 & 0.03 & 0.02 & -0.02 & 0.07 & 1.20 & 0.231 \\
\hline Total & 0.00 & 0.02 & -0.03 & 0.03 & -0.09 & 0.931 & -0.07 & 0.04 & -0.14 & 0.01 & -1.82 & 0.069 \\
\hline \multicolumn{13}{|l|}{ Intercepts } \\
\hline Child Attention & 2.00 & 0.60 & 0.82 & 3.19 & 3.32 & 0.001 & 3.24 & 0.67 & 1.93 & 4.55 & 4.84 & $<.001$ \\
\hline Parental Supportiveness & 0.14 & 0.62 & -1.07 & 1.36 & 0.23 & 0.815 & 0.82 & 0.89 & -0.93 & 2.57 & 0.92 & 0.359 \\
\hline Child Engagement of Parent & 0.50 & 0.49 & -0.45 & 1.46 & 1.03 & 0.301 & 1.01 & 0.63 & -0.23 & 2.25 & 1.59 & 0.111 \\
\hline Parental Intrusiveness & 4.13 & 0.75 & 2.65 & 5.60 & 5.49 & $<.001$ & 2.58 & 0.98 & 0.65 & 4.51 & 2.62 & 0.009 \\
\hline Parental Negative Regard & 2.57 & 0.53 & 1.53 & 3.60 & 4.85 & $<.001$ & 2.74 & 0.97 & 0.84 & 4.63 & 2.83 & 0.005 \\
\hline Child Negativity to Parent & 3.30 & 0.79 & 1.74 & 4.86 & 4.15 & $<.001$ & 2.80 & 1.13 & 0.58 & 5.02 & 2.47 & 0.014 \\
\hline Maternal Distress & 2.79 & 0.15 & 2.50 & 3.08 & 18.81 & $<.001$ & 3.04 & 0.14 & 2.77 & 3.32 & 21.57 & $<.001$ \\
\hline Parent-Child Dysfunction & 2.51 & 0.28 & 1.96 & 3.06 & 8.92 & $<.001$ & 3.70 & 0.30 & 3.10 & 4.29 & 12.22 & $<.001$ \\
\hline Parental Dep. Symptoms & 1.45 & 0.12 & 1.21 & 1.69 & 12.04 & $<.001$ & 1.43 & 0.07 & 1.29 & 1.57 & 19.94 & $<.001$ \\
\hline HOME & 6.79 & 0.66 & 5.50 & 8.09 & 10.27 & $<.001$ & 10.98 & 0.86 & 9.29 & 12.67 & 12.73 & $<.001$ \\
\hline Child Cognition (14m) & 8.89 & 1.51 & 5.94 & 11.84 & 5.91 & $<.001$ & 6.41 & 0.96 & 4.53 & 8.30 & 6.67 & $<.001$ \\
\hline Child Vocabulary (36m) & 3.09 & 1.18 & 0.78 & 5.40 & 2.62 & 0.009 & 1.92 & 1.00 & -0.03 & 3.87 & 1.93 & 0.054 \\
\hline Maternal Education & 2.29 & 0.11 & 2.08 & 2.50 & 21.68 & $<.001$ & 2.59 & 0.11 & 2.38 & 2.81 & 23.70 & $<.001$ \\
\hline Gestational Age & 2.40 & 0.45 & 1.53 & 3.27 & 5.39 & $<.001$ & 2.46 & 0.31 & 1.85 & 3.07 & 7.90 & $<.001$ \\
\hline Gender $(1=$ male $)$ & 1.17 & 0.14 & 0.89 & 1.45 & 8.12 & $<.001$ & 0.99 & 0.08 & 0.83 & 1.15 & 12.17 & $<.001$ \\
\hline Joint Attention & .00 & & .00 & .00 & - & - & .00 & & .00 & .00 & - & - \\
\hline Negative Interaction & .00 & & .00 & .00 & - & - & .00 & & .00 & .00 & - & - \\
\hline Maternal Distress & .00 & & .00 & .00 & - & - & .00 & & .00 & .00 & - & - \\
\hline
\end{tabular}


DIRECT INDIRECT INFLUENCES VOCABULARY DEVELOPMENT

\begin{tabular}{|c|c|c|c|c|c|c|c|c|c|c|c|c|}
\hline & \multicolumn{6}{|c|}{ Black/African American } & \multicolumn{6}{|c|}{ White/European American } \\
\hline & $\begin{array}{c}\text { Std. } \\
\text { Estimate } \\
(\beta)\end{array}$ & $S E$ & $\begin{array}{l}95 \% \text { CI } \\
\text { (Lower) }\end{array}$ & $\begin{array}{l}95 \% \text { CI } \\
\text { (Upper) }\end{array}$ & $z$ & $p$ & $\begin{array}{c}\text { Std. } \\
\text { Estimate } \\
(\beta)\end{array}$ & $S E$ & $\begin{array}{l}95 \% \text { CI } \\
\text { (Lower) }\end{array}$ & $\begin{array}{l}95 \% \text { CI } \\
\text { (Upper) }\end{array}$ & $z$ & $p$ \\
\hline \multicolumn{13}{|l|}{ Variances } \\
\hline Child Attention & 0.55 & 0.13 & 0.30 & 0.80 & 4.38 & $<.001$ & 0.60 & 0.11 & 0.38 & 0.81 & 5.43 & $<.001$ \\
\hline Parental Supportiveness & 0.36 & 0.13 & 0.11 & 0.62 & 2.82 & 0.005 & 0.24 & 0.12 & 0.01 & 0.47 & 2.04 & 0.041 \\
\hline Child Engagement of Parent & 0.62 & 0.11 & 0.41 & 0.82 & 5.87 & $<.001$ & 0.59 & 0.07 & 0.45 & 0.73 & 8.27 & $<.001$ \\
\hline Parental Intrusiveness & 0.16 & 0.23 & -0.29 & 0.61 & 0.71 & 0.479 & 0.53 & 0.15 & 0.24 & 0.83 & 3.52 & $<.001$ \\
\hline Parental Negative Regard & 0.82 & 0.10 & 0.63 & 1.02 & 8.32 & $<.001$ & 0.63 & 0.12 & 0.40 & 0.86 & 5.45 & $<.001$ \\
\hline Child Negativity to Parent & 0.60 & 0.14 & 0.33 & 0.88 & 4.26 & $<.001$ & 0.30 & 0.15 & 0.00 & 0.60 & 1.96 & 0.050 \\
\hline Maternal Distress & 0.17 & 0.25 & -0.33 & 0.66 & 0.65 & 0.513 & 0.52 & 0.11 & 0.31 & 0.73 & 4.89 & $<.001$ \\
\hline Parent-Child Dysfunction & 0.72 & 0.10 & 0.53 & 0.90 & 7.48 & $<.001$ & 0.69 & 0.10 & 0.49 & 0.90 & 6.64 & $<.001$ \\
\hline Parental Dep. Symptoms & 0.64 & 0.13 & 0.38 & 0.89 & 4.91 & $<.001$ & 0.65 & 0.11 & 0.43 & 0.87 & 5.72 & $<.001$ \\
\hline Child Vocabulary $(36 \mathrm{~m})$ & 0.80 & 0.08 & 0.64 & 0.95 & 10.02 & $<.001$ & 0.70 & 0.06 & 0.58 & 0.82 & 11.85 & $<.001$ \\
\hline Gender $(1=$ male $)$ & 1.00 & 0.00 & 1.00 & 1.00 & - & - & 1.00 & 0.00 & 1.00 & 1.00 & - & - \\
\hline Maternal Education & 1.00 & 0.00 & 1.00 & 1.00 & - & - & 1.00 & 0.00 & 1.00 & 1.00 & - & _ \\
\hline Child Cognition & 0.84 & 0.09 & 0.65 & 1.02 & 8.90 & $<.001$ & 0.96 & 0.03 & 0.90 & 1.02 & 30.49 & $<.001$ \\
\hline Gestational Age & 1.00 & 0.00 & 1.00 & 1.00 & - & - & 1.00 & 0.00 & 1.00 & 1.00 & - & 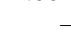 \\
\hline HOME & 0.86 & 0.07 & 0.73 & 1.00 & 12.67 & $<.001$ & 0.77 & 0.07 & 0.63 & 0.91 & 10.55 & $<.001$ \\
\hline Joint Attention & 0.68 & 0.19 & 0.30 & 1.05 & 3.55 & $<.001$ & 0.86 & 0.08 & 0.70 & 1.01 & 10.95 & $<.001$ \\
\hline Negative Interaction & 0.92 & 0.10 & 0.73 & 1.12 & 9.28 & $<.001$ & 0.98 & 0.04 & 0.91 & 1.05 & 27.49 & $<.001$ \\
\hline Maternal Distress & 1.00 & 0.00 & 1.00 & 1.00 & - & - & 1.00 & 0.00 & 1.00 & 1.00 & 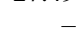 & - \\
\hline
\end{tabular}

Note: $* * * p<.001, * * p<.01, * p<.05$ 